Article

\title{
Identification of Shrinking Cities on the Main Island of Taiwan Based on Census Data and Population Registers: A Spatial Analysis
}

Di Hu (1)

Citation: $\mathrm{Hu}$, D. Identification of Shrinking Cities on the Main Island of Taiwan Based on Census Data and Population Registers: A Spatial Analysis. ISPRS Int. J. Geo-Inf. 2021, 10, 694. https://doi.org/10.3390/ ijgi10100694

Academic Editors: Martin Behnisch Tobias Krüger and Wolfgang Kainz

Received: 26 August 2021

Accepted: 12 October 2021

Published: 14 October 202

Publisher's Note: MDPI stays neutral with regard to jurisdictional claims in published maps and institutional affiliations.

Copyright: (C) 2021 by the author. Licensee MDPI, Basel, Switzerland. This article is an open access article distributed under the terms and conditions of the Creative Commons Attribution (CC BY) license (https:// creativecommons.org/licenses/by/ $4.0 /)$
Department of Land Economics, National Chengchi University, Taipei City 11605, Taiwan; 104257504@nccu.edu.tw

\begin{abstract}
At the end of the 20th century, the phenomenon of urban shrinkage received widespread attention, with population decline as its core characteristic. In 2020, the Taiwanese population had negative growth and faced a low fertility rate and an aging population. This study used exploratory spatial data analysis to identify shrinking cities in Taiwan based on census data and population registers. The results indicated that Taiwan has 11 shrinking counties and 202 shrinking towns. Urban shrinkage occurred in the 1980s and continued from the suburbanization stage to the re-urbanization stage. Five types of spatial patterns in the 11 shrinking counties were observed. In the majority of the shrinking counties, towns with high population densities were unable to avoid shrinkage. A global spatial autocorrelation analysis indicated that shrinkage and non-shrinkage have become increasingly apparent at the town level since 2005. A local spatial autocorrelation analysis indicates that the spatial clustering of towns with population growth or decline from 2000 to 2020 has changed. Based on each town's development, a two-step cluster analysis was conducted in which all towns were divided into four categories. Shrinking towns exist in each category, but with a different proportion. Based on the results of two-step cluster analysis combined with spatial analysis, this study discovered that both urbanization and suburbanization cause shrinkage in Taiwan, but the affected localities are distinct. For most shrinking counties, their spatial model indicates a relationship between shrinking and the urbanization of their towns. Keelung City and Chiayi City have the most potential to reverse the shrinkage. This study helps authorities better manage growth and implement regional revitalization.
\end{abstract}

Keywords: census data; population registers; shrinking city; exploratory spatial data analysis; spatial autocorrelation analysis; two-step cluster analysis

\section{Introduction}

In the mid to late 20th century, as the global population multiplied, the global urbanization rate increased. The urbanization rate rose particularly rapidly in developing countries. However, population expansion and growth are no longer only relevant to cities. Urban shrinkage, characterized by population decline, has become a worldwide phenomenon [1,2]. In 2008, United Nations-Habitat released a report entitled "State of the World's Cities 2008/2009: Harmonious Cities." Chapter 1, Section 4 was entitled "Shrinking Cities." This chapter indicated that cities do not only grow but also experience rising and falling cycles; recessions and population shrinkage lead to permanent changes in urban structures. Evidence has revealed that several cities in all regions of the world, both in developed and developing countries, shrank from 1990 to 2000 [3]. Since the beginning of the 21st century, several cities across Europe and North America have experienced population decline, an increase in vacant space, and the underutilization of urban infrastructure [4]. Since then, the phenomenon of city shrinkage also began to appear in China [5-7], Japan [8,9], and South Korea [10-12].

The concept of shrinking cities was first developed to describe the hollowing out of a city due to massive population loss $[13,14]$. The term "shrinking city" comes from the 
German phrase Schrumpfende Städte, coined by Häußermann and Siebe [15]. It describes the phenomena of deindustrialization, population decline, and economic recession in German cities. Urban shrinkage usually manifests as population decline, increases in unemployment, and decreases in a neighborhood's quality of life [16,17]. Urban shrinkage does not refer to a decrease in the physical area of metropolitan jurisdictions or developed areas. Rather, the term denotes a decrease in average population density [18].

In 2004, 30 scholars and experts from 14 countries established the Shrinking Cities International Research Network (SCIRN) at the Institute of Urban and Regional Development of the University of California, Berkeley. The network defined shrinking cities as densely populated urban areas with at least 10,000 inhabitants that have experienced population decline across most areas for more than two years and are undergoing an economic transformation characterized by an inevitable structural crisis [19]. This definition is used not only in empirical research but in the academic community. When Hollander et al. [20] examined the basic theory of planning shrinking cities, they cited the SCIRN report in their definition of shrinking cities. In terms of the core issue, the majority of researchers agree that population decline is the best criterion for determining whether a city is shrinking [21]. Population growth is used as the primary indicator of the trajectory of urban development in part because of the availability of data, and in part for the sake of consistency with previous research [1]. However, because of the substantial differences in urban development among countries and regions, researchers have not reached a consensus regarding the criteria for determining whether a city is shrinking [22].

Shrinking cities is a neutral term. In the discourse surrounding urban population decline, economic recession, and the phenomena they cause, derogatory terms such as urban decline and ghost towns are often used. Shrinking cities connotes population decline and the issues it causes. By contrast, urban decline connotes economic issues and the social, material, and environmental problems caused by economic downturns. Although economic recessions can lead to population decline, no absolute causal relationship has been established between them [1]. A city with a declining population can maintain economic growth by improving production efficiency and through industrial upgrades, and a decline in population can also improve problems of crowding in urban environments. Residents of a city in a recession may continue to thrive [23]. The term ghost town carries a strong derogatory connotation and represents an extreme result of urban shrinkage. The term shrinking city, as used in this study, refers to a municipality that has experienced sustained population decline over a certain period of time and changes in its resources for urban development.

Taiwan's urbanization rate accelerated along with the rapid population growth of the mid-20th century. Under the definition of urbanization as the proportion of people living in towns with more than 50,000 residents, the degree of urbanization in Taiwan increased from 33\% in 1956 to $78 \%$ in 2000 [24]. According to the United Nations definition, in which 20,000 residents is the standard for urban, the degree of urbanization in Taiwan in 2000 was nearly 95\% [25]. Urban development usually involves four stages: urbanization, suburbanization, counter-urbanization, and re-urbanization [26]. An empirical study by Liu et al. [24] revealed that the first three stages of urban development in Taiwan from 1950 to 2000 followed those of modern European countries, as defined by Van den Berg et al. [27]. The period between 1950 and 1970 represents the urbanization stage. The period between 1970 and 1990 represents the end of the urbanization stage and the beginning of suburbanization. The period between 1990 and 2000 represents the suburbanization stage. Suburbanization is one of the main causes of urban population decline $[17,28]$. During the 1950s and 1960s in the United States, the center of urban areas shrank, whereas the suburbs grew. The early shrinking process was triggered by suburbanization, and suburban sprawl led to a sharp decline in the populations of city centers [29]. Because Taiwan has been following a similar pattern to that of some European countries and the United States, Taiwan, too, will likely face the fourth stage of shrinkage. 
However, growth is still considered in the traditional paradigm of thought as a core element of Taiwan's urban development. Various problems caused by city shrinkage have been investigated in Taiwan. However, the concept of city shrinkage has not yet been acknowledged by the Taiwanese Government, academia, or society. As in many parts of the world, the concept of shrinking cities has been permanently stigmatized in the field of urban planning in Taiwan [30]. During Kaohsiung City's mayoral election in 2017, the mayorelect promised to increase Kaohsiung's population from 2.78 million to 5 million [31]. Taiwan's most revised Spatial Planning Act was released in April 2020. According to Article 3, of Chapter I, General Provisions, the term "growth management" was added to the terminology in the law, but "urban shrinkage," "shrinking city," or "smart decline" were not added [32]. Their inclusion in towns' laws is imperative because the actual size of Taiwan's towns is vastly different from that which is estimated by urban planning, and therefore, continuous population growth and urban expansion without incorporation of analyses of urban shrinkage is not feasible. Taiwan has implemented plans for 433 nationwide urban development sites, with a total planned area of $4815 \mathrm{~km}^{2}$, accounting for $13 \%$ of Taiwan's land area. In 2019, the population of the areas in the nationwide urban development plan was 18.517 million, only $73.3 \%$ of the planned population of 25.241 million. Taiwan's total population peaked at 23.603 million in December 2019 and has since exhibited negative growth. In addition, Taiwan has faced the issues of a declining birthrate and an aging population [33], which represent challenges to the sustainable development of cities and are causes of urban shrinkage. Continuous population growth and urban expansion are not sustainable development models.

Academics and policymakers must adroitly address the phenomenon of urban shrinkage and the problems caused by the incongruous combination of Taiwan's population decline and the push for urban development. Academic research in Taiwan had not addressed urban shrinkage until ten years ago. In empirical studies on Taiwan's urban shrinkage, the data used to ascertain shrinkage has been one-sided, and no shrinkage identification has been conducted for the counties and towns on Taiwan's main island. A 2014 study identified 295 shrinking towns based on population registers and employment surveys [34]. A 2017 study identified shrinking towns in 19 counties based on census data [35]. A 2018 study identified 175 shrinking towns based on population registers [36]. Determining population based on census data or population registers without nuance in Taiwan constitutes a hindrance that may lead to inaccurate assessments. Pallagst [37] indicated that the unemployed population should not be considered in the evaluation of urban shrinkage. Changes in the unemployed population are closely related to macroeconomic factors. Although the unemployed population in cities increases during economic downturns, this does not necessarily mean that cities will also experience population decline. Therefore, the choice of population data is crucial in the evaluation of shrinkage.

This study used census data and population registers to examine Taiwan's urban shrinkage and nonurban shrinkage. The shrinking city phenomenon in Taiwan's counties and towns was identified through an analysis of population variation, time trajectories, and spatial patterns. In addition, changes in spatial demographics and their causes were explored. Finally, cluster analysis was used to explore the relationship between urbanization and shrinkage.

\section{Materials and Methods}

\subsection{Study Area}

The main island of Taiwan was selected as the area for investigation (Figure 1a). The characteristics of urban development on Taiwan's outlying islands, such as population flow, economic development, transportation facilities, and spatial morphology, are considerably different from those of urban development on Taiwan's main island. Therefore, the outlying islands were outside the scope of the study. The main island of Taiwan consists of 19 counties, 6 of which are special municipalities, and 13 of which are provincial cities. Each city governs a certain number of districts, and each county governs a certain number 
of towns. No distinction is made between the terms for county and city to describe urban environments, nor is one made between district and town. For the sake of convenience, this study referred to municipalities and provincial cities as counties and districts and referred to towns as towns. Therefore, this study includes 19 counties and 349 towns.

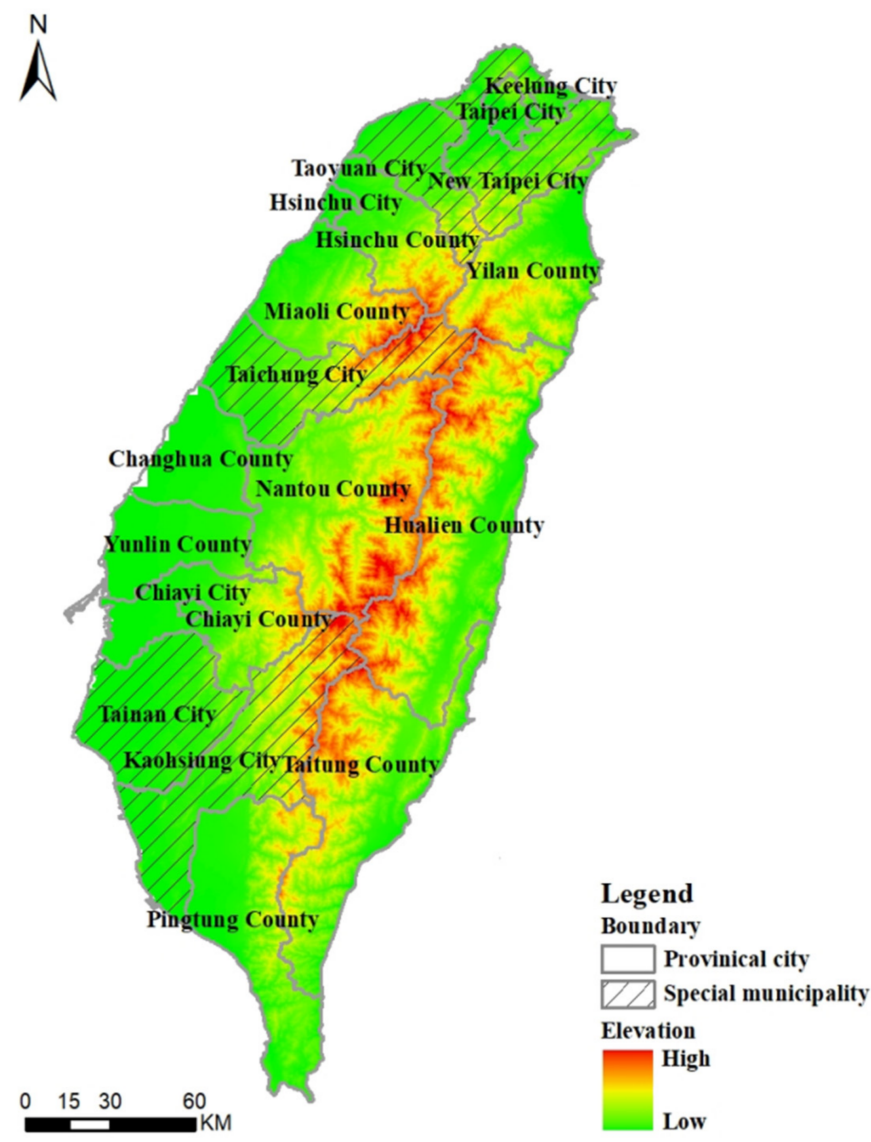

(a)

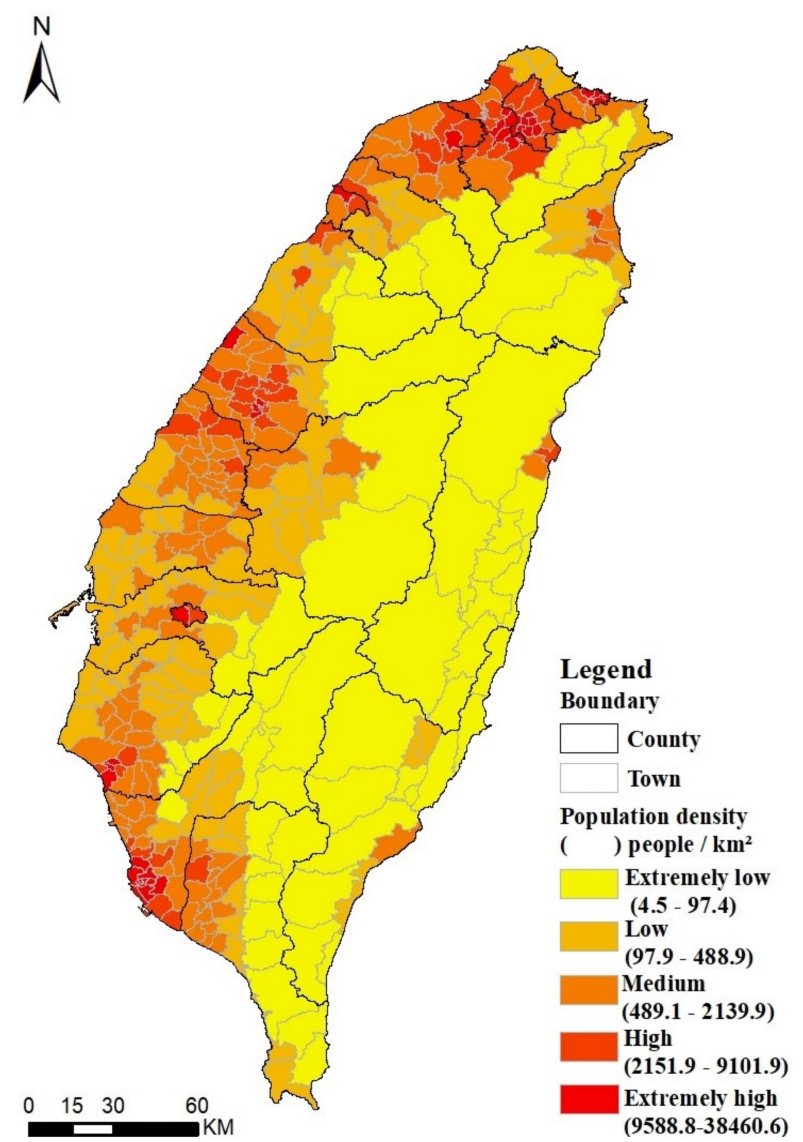

(b)

Figure 1. Study Area: (a) Scope of empirical research; (b) Density of the registered population in 2020.

In 2020, Taiwan's per capita gross domestic product reached US\$28,400. The majority of Taiwan's population and its industrial development are concentrated in the western coastal plain. The Taiwan High-Speed Rail, which began operations in 2007, extends along the western coastal plain. Taiwan's six special municipalities are also all located in the western coastal plain, and in 2020, their population accounted for $68.8 \%$ of Taiwan's registered population. Existing data sets have substantially varied in the scale of towns (Table 1). According to the 349 towns' registered population in 2020, using the geometrical interval classification function of the ArcGis software (version 10.3) classifies the population density. Population density is divided into five grades: extremely low, low, medium, high, and extremely high (Figure 1b). The population density of the west coast of Taiwan is considerably higher than that of other areas. The vast majority of areas with extremely low population density are mountainous areas. The area with the highest population density is part of the Greater Taipei Metropolitan Area, comprising Taipei City, New Taipei City, and Keelung City. In 2020, the total registered population of the Taipei Metropolitan Area accounted for $29.7 \%$ of Taiwan's total population. 
Table 1. Number of towns and varying population.

\begin{tabular}{cccc}
\hline \multirow{2}{*}{ Town Population } & \multicolumn{3}{c}{ Number of Towns } \\
\cline { 2 - 4 } & $\begin{array}{c}\text { 2010 Census } \\
\text { Population }\end{array}$ & $\begin{array}{c}\text { 2010 Registered } \\
\text { Population }\end{array}$ & $\begin{array}{c}\text { 2020 Registered } \\
\text { Population }\end{array}$ \\
\hline $1-2499$ & 10 & 1 & 1 \\
$2500-9999$ & 60 & 48 & 53 \\
$10,000-49,999$ & 157 & 171 & 170 \\
$50,000-199,999$ & 94 & 104 & 96 \\
$200,000-600,000$ & 28 & 25 & 29 \\
\hline
\end{tabular}

\subsection{Data Sources}

The data used in this study consisted of census data and population registers (Table 2). The household registration system plays a vital role in Taiwan and is closely related to military service, elections, education, the purchase of houses, and social welfare [38]. The seventh population and housing census were conducted at the end of 2020, but because the results will not be released until 2022, they could not be used in this study.

Table 2. Comparison of registered and census populations.

\begin{tabular}{ccc}
\hline Category & Registered Population & Census Population \\
\hline Definition & $\begin{array}{c}\text { Regardless of whether they } \\
\text { live in the household } \\
\text { registration address, they are } \\
\text { part of the area's population }\end{array}$ & $\begin{array}{c}\text { Population residing or expected to } \\
\text { reside for 6 months in a particular } \\
\text { area }\end{array}$ \\
\hline Source & Household registration & Population and housing census \\
Composition & Counties and towns & $\begin{array}{c}\text { The first five censuses only } \\
\text { included counties; the 2010 census } \\
\text { included counties and towns }\end{array}$ \\
\hline Cycle & Every month & Every 10 years \\
\hline $\begin{array}{c}\text { Materials used in this } \\
\text { study (year) }\end{array}$ & $2000,2005,2010,2015$, and \\
2020 & $1980,1990,2000$, and 2010 \\
\hline
\end{tabular}

\subsection{Identification of Shrinkage}

In the middle of the 20th century, because the population mobility of Taiwan was low, the registered population and the number of permanent residents (census) were similar. After economic and social development, the population began to move frequently. Since the end of the 20th century, Taiwan's registered population has not been an accurate representation of the number of people residing on the island [39-41]. Only by combining the registered and census populations can population decline in cities be determined and the shrinking of cities be identified.

The census population and registered population are inherently related. The census population refers to the number of people who live in a county or town for more than 6 months during the census period. In essence, the census population is equal to the number of locals plus nonlocals. The total number of people in the registered population refers to the tally of people born in that locality and those who immigrated to that locality. Eight possible reasons explain the discrepancy between the total number in the census population and the total number in the registered population (Table 3), the most common being nonlocals, and locals, leaving because of a lack of employment opportunities, leading to the census population being lower than the registered population. 
Table 3. Relationship between census population and registered population.

\begin{tabular}{ccccc}
\hline Relationship & Possibility & Census Population & Registered Population \\
\hline & 1 & Locals increase, nonlocals decrease & Locals increase \\
Census population $<$ & 2 & Locals decrease, nonlocals maintain & Locals decrease \\
registered population & 3 & Locals decrease, nonlocals decrease & Locals decrease \\
& 4 & Locals maintain, nonlocals decrease & Locals maintain \\
\hline Census population $>$ & 5 & Locals increase, nonlocals increase & Locals increase \\
registered population & 6 & Locals decrease, nonlocals increase & Locals decrease \\
& 7 & Locals decrease, nonlocals constant & Locals decrease \\
& 8 & Locals maintain, nonlocals increase & Locals maintain \\
\hline
\end{tabular}

After consideration of the characteristics and sources of the population data, a shrinking city was defined as follows: counties where the census population was lower than the registered population in 2010 and the registered population in 2020 was lower than the registered population in 2010. A shrinking town was defined as a town in which the census population was lower than the registered population in 2010 and the registered population in 2020 was lower than the registered population in 2010.

\subsection{Classification of Shrinkage}

\subsubsection{Classification of Shrinking Counties}

Census population data for 1980, 1990, 2000, and 2010 were used to identify shrinking counties with the largest changes in population. The equation for calculating changes in the census population of a shrinking county is as follows:

$$
C_{c p}=\left(P_{\max }-P_{2010}\right) / P_{\max }
$$

In Equation (1), $P_{\max }$ represents the maximum census population of each shrinking county among the 1980, 1990, 2000, and 2010 census populations; $P_{2010}$ represents the census population in each shrinking county in 2010. Shrinking counties were classified on the basis of changes in the census population.

\subsubsection{Classification of Shrinking Towns}

The 2010 population and housing census was the first survey of towns' census populations. Because of a lack of observational data for comparison, population decline in shrinking towns can only be calculated by using registered population data. The registered population for the majority of shrinking towns reached a maximum between 2000 and 2010. For the sake of convenience and to demonstrate the latest changes in population, population decline in shrinking towns was calculated using registered population data from 2010 to 2020. The equation for calculating changes in the registered population of shrinking towns is as follows:

$$
C_{r p}=\left(P_{2020}-P_{2010}\right) / P_{2010}
$$

In Equation (2), $P_{2020}$ represents each town's registered population in 2020; $P_{2010}$ represents each town's population in 2010. Shrinking towns were also classified on the basis of changes in the registered population.

\subsection{Time Trajectories of Shrinking Counties}

For counties determined to be shrinking, census population data were used to analyze the time trajectory of their shrinkage. The work of Turoke [1], Wiechmann et al. [42], Alves et al. [43], and Du et al. [44] was referenced to divide the time trajectories of population decline into the following five categories: early shrinkage, mid-term shrinkage, recent shrinkage, continuous shrinkage, and interrupted shrinkage (Table 4, Figure 2). The 
different time trajectories of various shrinking counties classify the severity of shrinkage from a time perspective and provide a reference for shrinking governance.

Table 4. Criteria for determining the time trajectory.

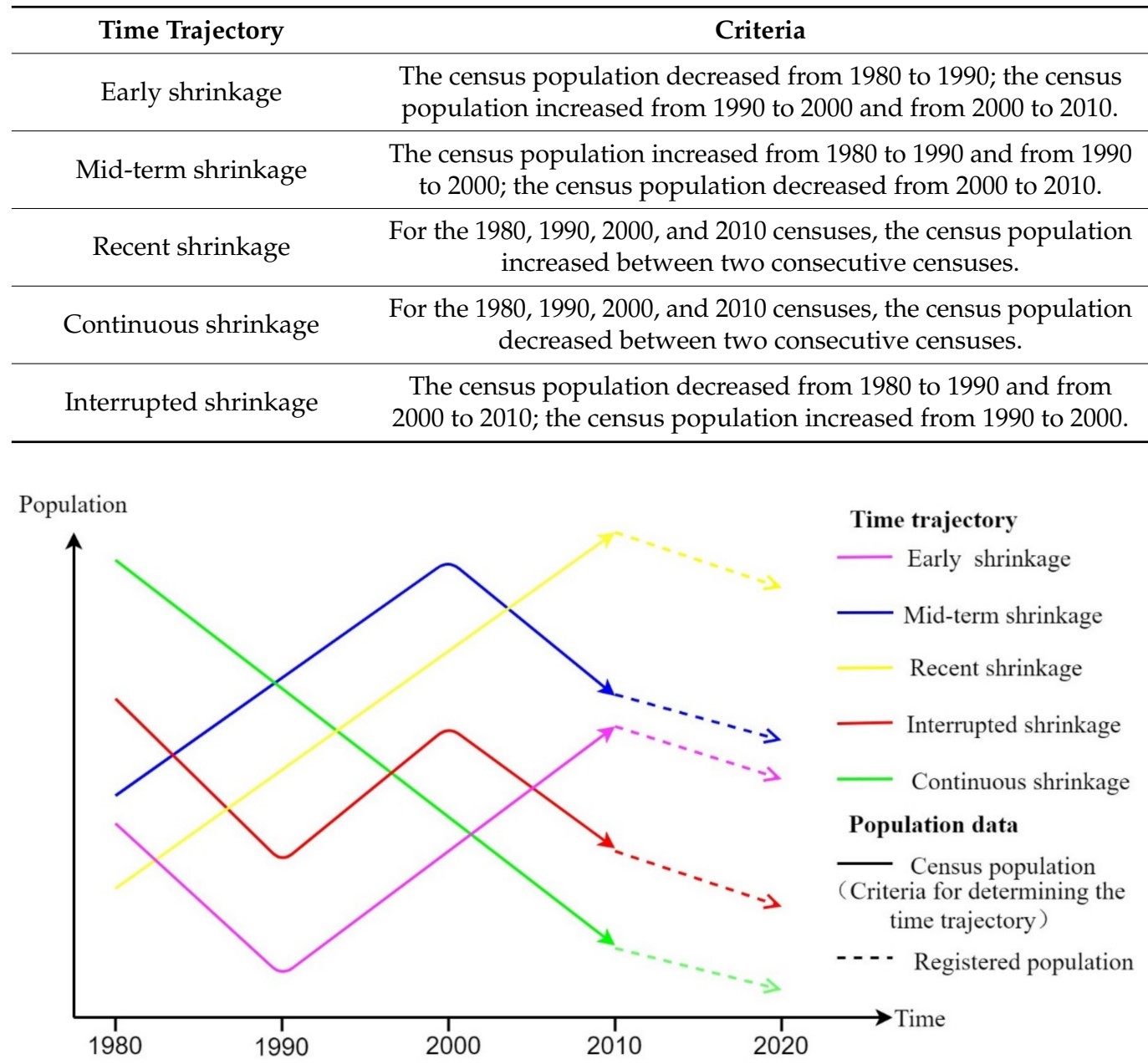

Figure 2. Time trajectories of shrinking counties.

The identification of a shrinking county was based on its census population and registered population. A shrinking county is defined as a county in which the census population was lower than the registered population in 2010, and the registered population in 2020 was lower than the registered population in 2010. Only the census population in 1980, 1990, 2000, and 2010 is used to classify the time trajectory of shrinking counties (Figure 2). According to the time trajectory, the registered population of all shrinking counties decreased from 2010 to 2020 (Figure 2). Regarding a shrinking county with recent shrinkage, although its census population had been increasing from 1980 to 2010, its census population in 2010 was smaller than its registered population, and the registered population has decreased since 2010.

\subsection{Spatial Pattern of Shrinking Counties}

A spatial analysis of shrinkage revealed the spatial patterns of shrinkage in each county. Shrinking counties were classified on the basis of the geographic relationships among their shrinking and non-shrinking towns. Zhang et al. [45] divided urban shrinkage into three spatial patterns. In this study, shrinking counties were categorized based on six spatial patterns: global shrinkage, semiglobal shrinkage, central shrinkage, perforated shrinkage, two-sided shrinkage, and circular shrinkage (Table 5). Understanding the spatial 
pattern of shrinking counties will provide a reference for shrinking governance, especially for selecting areas that may reverse shrinking.

Table 5. Criteria for determining the spatial pattern of shrinking counties.

\begin{tabular}{cr}
\hline \multicolumn{1}{c}{ Spatial Pattern } & Criteria \\
\hline Global shrinkage & All towns were shrinking towns. \\
\hline Semiglobal shrinkage & Shrinking towns were geographically adjacent and concentrated to one side of the county. \\
\hline Central shrinkage & The majority of the shrinking towns were located at the center of the county. \\
\hline $\begin{array}{c}\text { Perforated shrinkage } \\
\text { Two-sided shrinkage }\end{array}$ & The majority of the shrinking towns were not adjacent; shrinking and non-shrinking towns were \\
scattered throughout the county.
\end{tabular}

To investigate the relationship between shrinking spatial patterns and each county's internal development, ArcGIS was used to analyze the shrinking of towns in each county and the population density of registered households. The population density of the towns was determined using registered population data from August 2020. The population density of the towns was classified using the geometric interval tool in ArcGIS. When categorizing the population density of shrinking counties, no shrinking counties used a consistent standard. The classification of each shrinking county was independent. Additionally, to explore the relationship between the shrinking spatial pattern and the overall development of Taiwan's main island, cluster analysis (see Section 2.8) was conducted for 349 towns. Based on the cluster analysis results, the relationship between urbanization and the spatial pattern of shrinking counties was also discussed.

\subsection{Exploratory Spatial Data Analysis}

Exploratory Spatial Data Analysis (ESDA) combines mathematical statistics and graphs to identify and model spatial characteristics [46]. This method involves exploring the spatial relevance of adjacent areas through the statistical description and visual analysis of the distribution of the research objects. The core feature of this method is the measurement of spatial relevance, which can describe and reveal an object's spatial distribution. ESDA is an effective method of measuring regional differences in spatial analysis and is used in many fields, such as determining the spatial distribution of animal diseases [47] and the quality of land urbanization [48].

ESDA consists of two indicators: global spatial autocorrelation and local spatial autocorrelation. Spatial autocorrelation refers to adjacent areas having similar variable values. Cases in which high-value areas are clustered with other high-value areas and low-value areas are clustered with other low-value areas represent positive spatial autocorrelations. Cases in which high-value and low-value areas are clustered together have negative spatial autocorrelations. Cases in which high- and low-value areas are randomly distributed have no spatial autocorrelation.

To characterize changes in the spatial distribution of the population of registered households in Taiwan, this study analyzed global and local spatial autocorrelations of the changes in each town's registered population across four time periods: 2000-2005, 2005-2020, 2010-2015, and 2015-2020. The equation for calculating changes in a town's registered population is as follows:

$$
C_{t}=\left(P_{2}-P_{1}\right) / P_{1}
$$

In Equation (3), $P_{1}$ represents the registered population at the beginning of the time period, and $P_{2}$ represents the registered population at the end of the time period. A continuous decrease in population is the defining feature of shrinking cities. The spatial correlation of 
the change in the registered population can also be interpreted as the spatial correlation between shrinkage and non-shrinkage.

\subsubsection{Global Spatial Autocorrelation}

Global Moran's I is the most commonly used indicator of global spatial autocorrelation. It is also the most widely used indicator for identifying agglomeration behavior across an entire research area $[49,50]$. In this study, the Global Moran's I for the change in each town's registered population was calculated. The equation is as follows:

$$
I=\frac{\sum_{i=1}^{n} \sum_{j \neq i}^{n} W_{i j}\left(C_{i}-c\right)\left(c_{j}-\bar{C}\right)}{S^{2} \sum_{i=1}^{n} \sum_{j=1}^{n} W_{i j}}
$$

In Equation (4), $n$ represents the total number of towns, and $W_{i j}$ represents spatial weight (two towns with a common boundary are considered adjacent; if town $i$ is adjacent to town $j, W_{i j}$ is 1 . Otherwise, $W_{i j}$ is 0$)$. $C_{i}$ represents the change in the registered population of town $i ; C_{j}$ represents the change in the registered population of town $j ; \bar{c}$ represents the town's average registered population; $S^{2}$ represents sample variance. The Global Moran's $I$ can be between -1 and 1 . A positive value for Global Moran's I indicates a positive spatial correlation. Higher positive values indicate more pronounced spatial correlations. A negative Global Moran's I indicates a negative spatial correlation. Lower negative values indicate more pronounced spatial differences. A Global Moran's I of 0 indicates randomness in the spatial correlation.

\subsubsection{Local Spatial Autocorrelation}

Because the Global Moran's I only reflects overall spatial clusters and does not reflect individual spatial clusters, Anselin [51] proposed local indicators of spatial association (LISAs). LISAs have two essential characteristics. First, they provide statistical information on each location and assesses their influence. Second, they establish a proportional relationship between the sum of the local statistics and the corresponding global statistics.

The Local Moran's I is an indicator used in the LISA analysis to determine the LISAs. In this study, the Local Moran's I for the change in the registered population of town $i$ was calculated to identify its surrounding spatial clustering. The equation is as follows:

$$
I_{i}=\frac{\left(c_{i}-\bar{C}\right)}{S^{2}} \sum_{j \neq i} W_{i j}\left(C_{j}-\bar{C}\right)
$$

In Equation (5), $I i>0$ indicates one of the following two situations: (1) a large increase in the registered population of town $i$ and in the registered populations of the surrounding towns; (2) a small increase in the registered population of town $i$ and in the registered populations of the surrounding towns. I $i<0$ indicates one of the following two situations: (1) a large increase in the registered population of town $i$ and a small increase in the registered populations of surrounding towns; (2) a small increase in the registered population of town $i$ and a large increase in the registered population of surrounding towns.

The Local Moran's I was calculated by using GeoDA software to derive the LISA cluster map. The cluster map indicates the type of spatial association according to the value's position and its spatial lag in the Moran scatter plot, thereby increasing the vital position. LISA subdivides clusters into five types: high-high clusters, high-low clusters, low-high clusters, low-low clusters, and nonsignificant.

The Global Moran's I and Local Moran's I were calculated using the GeoDa software. To maximize the impact of neighboring towns, "contiguity weight" and "queen contiguity" were selected, and "order of contiguity" was set to 1 in the GeoDA weight manager. 


\subsection{Analysis of Relationship between Urbanization and Shrinkage}

In this study, first, cluster analysis of 349 towns was conducted based on the development of each town; in addition, based on the results of the cluster analysis combined with the town's population and density, the town's urbanization type was determined. Second, GIS was used to analyze the relationship between urbanization and the shrinkage of towns. Finally, the impact of urbanization level on shrinkage was analyzed.

\subsubsection{Cluster ANALYSIS}

Cluster analysis is a statistical method to create a group and classify objects according to their features [52]. Kaufman et al. [53] defined cluster analysis as the classification of similar objects into groups, where the number and characteristics of groups are unknown. In each cluster, individuals have similar characteristics, but the differences in individual characteristics between different clusters are relatively substantial. Cluster analysis involves hierarchical clustering, k-means clustering, fuzzy c-means clustering, semi-supervised fuzzy c-means clustering, DBSCAN clustering, modified DBSCAN clustering, and twostep clustering.

Hierarchical cluster analysis can be divided into the bottom-up agglomeration method and top-down divisive method; the agglomerative method includes the single linkage method, complete linkage method, average linkage method, and Ward's minimum variance method; the divisive method primarily includes the splinter-average distance method [54]. The variables in hierarchical cluster analysis can be quantitative, binary, or count data. In SPSS software, a dendrogram or icicle plot, is used to determine the hierarchical cluster analysis. The hierarchical cluster analysis method is limited to smaller data files; mere hundreds of objects can be clustered.

The most common nonhierarchical cluster analysis method is k-means cluster analysis proposed by Macqueen [55]. The k-means cluster analysis method is limited to continuous data. K-means cluster analysis can be used to analyze large data files, but the algorithm requires specifying the number of clusters in advance. Hierarchical cluster analysis and k-means cluster analysis, as traditional clustering techniques, have some limitations; for example, they are only applicable to continuous variables, rest on the assumption of normality, and feature an arbitrary choice of the number of clusters [56-59].

The fuzzy c-means clustering algorithm was proposed by Bezdek et al. in 1984, and it applies to a wide variety of geostatistical data analysis problems [60]. Mai et al. [61] proposed a method to improve the fuzzy c-means clustering algorithm by moving the prototype of clusters to the expected centroids, which are predetermined based on samples. The proposed algorithm is used to detect change in multispectral satellite imagery at multiple time points [61].

Density-based spatial clustering of applications with noise (DBSCAN) is a typical densityclustering algorithm. DBSCAN is run with two parameters; the first is areas of the neighborhood, and the other is minimum points within these areas [52]. Pavlis et al. [62] proposed modified DBSCAN clustering that improves local sensitivity to variable point densities. In empirical research, the DBSCAN cluster is used to process geotagged photos [52,63], and the modified DBSCAN cluster is used to identify local retail agglomerations [62].

Two-step cluster analysis was first proposed by Chiu et al. [64] and is an intelligent clustering method that has been continuously developed and perfected in the last 20 years. Two-step cluster analysis overcomes the limitations of traditional cluster methods and has been used in empirical studies in various fields, such as social marketing [65], carbon dioxide emission [66], and psychiatric inpatient treatment [59]. Two-step cluster analysis involves two stages: pre-clustering and clustering.

The first step is the pre-clustering of cases. Original cases are grouped by constructing a cluster features tree [67]. Relevant records are investigated by distance to construct the classification feature tree; records in the same tree node have a high similarity, and records with comparable similarities will generate new nodes [66]. Two distance measures are available: Euclidean distance and log-likelihood distance. Euclidean distance can be used 
only when all of the variables are continuous. Log-likelihood distance can handle mixed attributes [56].

The second step is the clustering of cases. The standard hierarchical clustering algorithm on the pre-clusters is used [68]. A mode-based hierarchical technique is applied; similar to agglomerative hierarchical techniques, the pre-clusters are merged stepwise until all clusters are in one cluster [56]. Each clustering result is evaluated using the Akaike information criterion (AIC) or the Bayesian information criterion (BIC), which yield the final clustering result $[66,69]$.

Two-step cluster analysis is an intelligent clustering method that provides unique features. Two-step cluster analysis enables the automatic selection of the most-optimal number of clusters $[56,59,64,66]$. Two-step cluster analysis permits categorical and continuous data to be analyzed simultaneously $[59,65]$. Additionally, the two-step cluster analysis procedure can analyze large data files. In SPSS statistics (version 22), cluster analyses can be performed using the two-step, hierarchical, or k-means cluster analysis procedure. In two-step cluster analysis, the clustering algorithm works with standardized continuous variables. In SPSS statistics, continuous variables are z-scored by default to make them commensurable. In summary, to thoroughly demonstrate the differences in the towns development and analyze the characteristics of variables, a two-step cluster analysis was ultimately selected for cluster analysis of 349 towns.

\subsubsection{Variables of Cluster Analysis}

To ensure that the cluster analysis accurately indicates the differences in the towns' development, the five variables were set to be positive (Table 6). In other words, a town with a higher value has a higher level of development. The sources of variables include the 2010 Population and Housing census and the 2011 Industrial and Service Industry census.

Table 6. Variables, variable abbreviations, influencing factors, and variable units in cluster analysis.

\begin{tabular}{cccc}
\hline Variable & $\begin{array}{c}\text { Variable } \\
\text { Abbreviation }\end{array}$ & $\begin{array}{c}\text { Influencing } \\
\text { Factor }\end{array}$ & Variable Unit \\
\hline Population density & PD & $\begin{array}{c}\text { Urban-built } \\
\text { environment }\end{array}$ & people $/ \mathrm{km}^{2}$ \\
\hline $\begin{array}{c}\text { Proportion of population with } \\
\text { college degree or above }\end{array}$ & PPCD & Labor skills & $\%$ \\
\hline $\begin{array}{c}\text { Total annual production of } \\
\text { industrial and service industries }\end{array}$ & PISI & $\begin{array}{c}\text { Economic } \\
\text { development }\end{array}$ & $\begin{array}{c}100 \text { million yuan } \\
\text { (New Taiwan dollar) }\end{array}$ \\
\hline $\begin{array}{c}\text { Proportion of nonagricultural, } \\
\text { non-forestry, non-fishery, and } \\
\text { non-animal husbandry } \\
\text { production personnel }\end{array}$ & PNPP & $\begin{array}{c}\text { Industrial } \\
\text { structure }\end{array}$ & $\%$ \\
\hline $\begin{array}{c}\text { Proportion of non-aged } \\
\text { population }(\leq 65 \text { years) }\end{array}$ & PNAP & $\begin{array}{c}\text { Population } \\
\text { structure }\end{array}$ & $\%$ \\
\hline
\end{tabular}

\section{Results and Analysis}

\subsection{Identification of the Results of Shrinkage}

\subsubsection{Identification of Shrinking Counties}

Among the 19 counties on the main island of Taiwan, 11 counties were identified as shrinking: Yilan County, Miaoli County, Changhua County, Nantou County, Yunlin County, Chiayi County, Pingtung County, Taitung County, Hualien County, Keelung City, and Chiayi City (Figure 3a). All 11 shrinking counties contain provincial cities. 


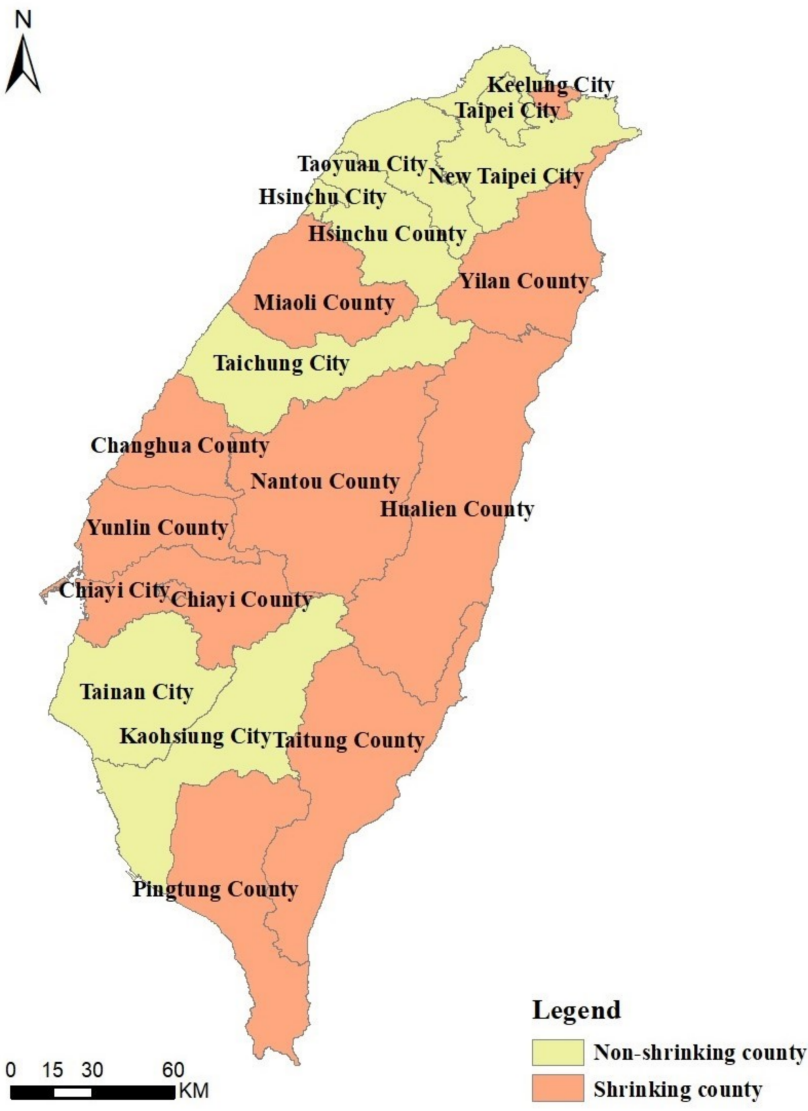

(a)

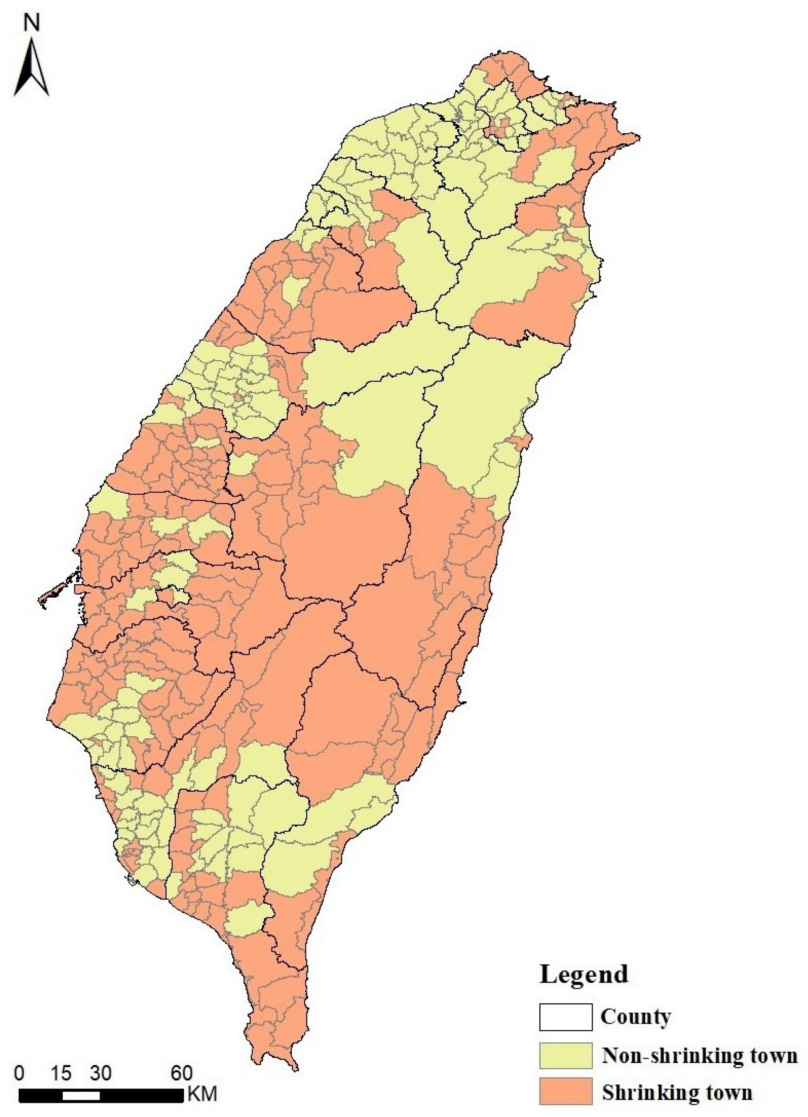

(b)

Figure 3. Spatial distribution of shrinking counties and towns: (a) shrinking counties; (b) shrinking towns.

\subsubsection{Identification of Shrinking Towns}

Among the 349 towns on Taiwan's main island, 202 were identified as shrinking (Figure 3b). The number of shrinking towns in the northern region was much lower than that in the other regions. Among the 19 counties, only Taoyuan City and Hsinchu City in the northern region did not contain shrinking towns (Table 7). All other counties, including the six municipalities directly under the control of the central government, contained shrinking areas. More than $70 \%$ of towns in Miaoli County, Changhua County, Nantou County, Yunlin County, Chiayi County, and Taitung County were identified as shrinking.

Table 7. Number of shrinking towns in each region and county.

\begin{tabular}{|c|c|c|c|c|c|}
\hline Region & All Towns & Shrinking Towns & County & All Towns & Shrinking Towns \\
\hline \multirow{7}{*}{ Northern region } & \multirow{7}{*}{89} & \multirow{7}{*}{27} & New Taipei City * & 29 & 9 \\
\hline & & & Taipei City * & 12 & 5 \\
\hline & & & Keelung City & 7 & 2 \\
\hline & & & Hsinchu City & 3 & 0 \\
\hline & & & Yilan County & 12 & 6 \\
\hline & & & Taoyuan City * & 13 & 0 \\
\hline & & & Hsinchu County & 13 & 5 \\
\hline \multirow{5}{*}{ Central region } & \multirow{5}{*}{106} & \multirow{5}{*}{74} & Taichung City * & 29 & 8 \\
\hline & & & Miaoli County & 18 & 15 \\
\hline & & & Changhua County & 26 & 22 \\
\hline & & & Nantou County & 13 & 11 \\
\hline & & & Yunlin County & 20 & 17 \\
\hline
\end{tabular}


Table 7. Cont.

\begin{tabular}{|c|c|c|c|c|c|}
\hline Region & All Towns & Shrinking Towns & County & All Towns & Shrinking Towns \\
\hline \multirow{5}{*}{ Southern Region } & \multirow{5}{*}{127} & \multirow{5}{*}{82} & Tainan City * & 37 & 25 \\
\hline & & & Kaohsiung City * & 38 & 20 \\
\hline & & & Chiayi City & 2 & 1 \\
\hline & & & Chiayi County & 18 & 15 \\
\hline & & & Pingtung County & 32 & 11 \\
\hline \multirow{2}{*}{ Eastern Region } & \multirow{2}{*}{27} & \multirow{2}{*}{20} & Taitung County & 14 & 11 \\
\hline & & & Hualien County & 13 & 9 \\
\hline
\end{tabular}

Note: ${ }^{*}$ indicates a special municipality.

\subsection{Classification of Shrinkage}

Shrinking counties were divided into the following categories on the basis of a decrease in census population: severe shrinkage, moderate shrinkage, mild shrinkage, and slight shrinkage. Among the 11 shrinking counties, two had severe shrinkage, three had moderate shrinkage, five had mild shrinkage, and one had slight shrinkage (Figure 4a). Among them, counties with severe shrinkage had a decrease in their census population of $20 \%$ to $30 \%$. Counties with moderate shrinkage had a decrease in their census population of $10 \%$ to $20 \%$. Counties with mild shrinkage had a decrease in their census population of less than $10 \%$. The census population of counties with slight shrinkage had not decreased, but the registered populations had decreased. The severity of shrinking was randomly distributed among the counties. The moderate shrinkage level was concentrated in Chiayi County, Nantou County, and Hualien County.

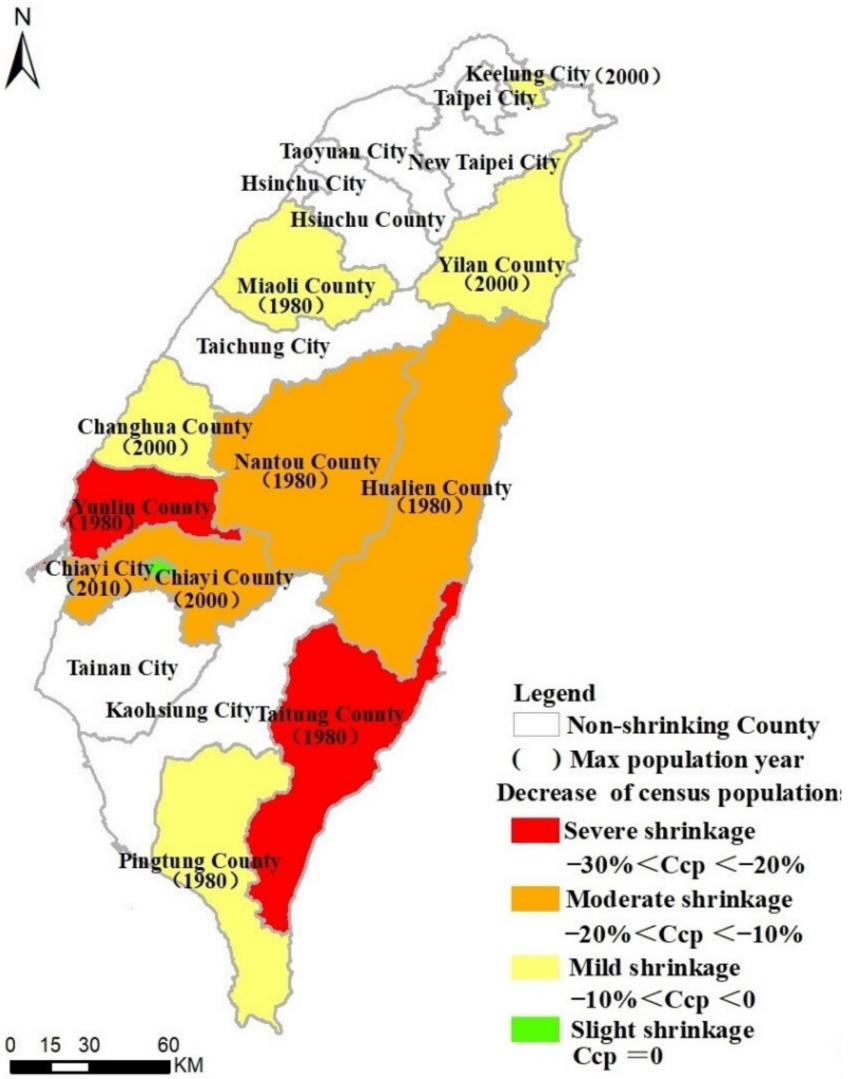

(a)

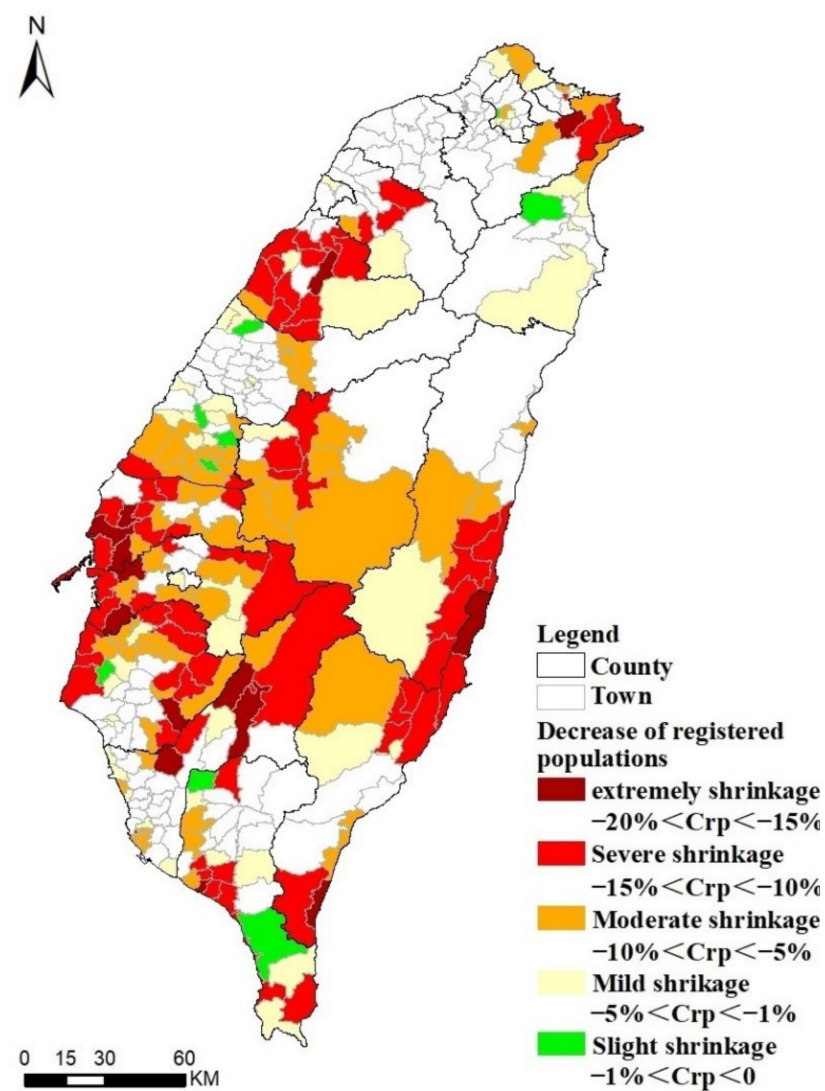

(b)

Figure 4. Classification of shrinkage: (a) decrease in census population of shrinking counties; (b) decrease in registered population of shrinking towns. 
The towns with shrinkage were divided into the following categories based on the level of decrease in the registered population: extreme shrinkage, severe shrinkage, moderate shrinkage, mild shrinkage, and slight shrinkage. Among the 202 shrinking towns, 15 had extreme shrinkage, 70 had severe shrinkage, 65 had moderate shrinkage, 42 had mild shrinkage, and 10 had slight shrinkage (Figure $4 \mathrm{~b}$ ).

\subsection{Analysis of the Temporal and Spatial Characteristics of Shrinking Areas}

3.3.1. Time Trajectories of County Shrinkage

Among the 11 shrinking counties, one had recent shrinkage, two had mid-term shrinkage, five had continuous shrinkage, and three had interrupted shrinkage (Figure 5). No county had early shrinkage. The decline in the census populations of Keelung City and Changhua County began in 2000; both had mid-term shrinkage. Taitung County, Hualien County, Yunlin County, Nantou County, and Pingtung County had continuous shrinkage since the decline in their census populations beginning in 1980. Yilan County, Miaoli County, and Chiayi County had interrupted shrinkage with their census population beginning to decline in 1980 but increasing from 1990 to 2000. Chiayi City had recent shrinkage, and its census population had been increasing from 1980 to 2010. The census population of Chiayi City in 2010 was smaller than the registered population, and the registered population exhibited a decreasing trend from 2010 to 2020. Chiayi City, which had recent shrinkage, is most likely to reverse the shrinkage from the time trajectory of shrinkage.

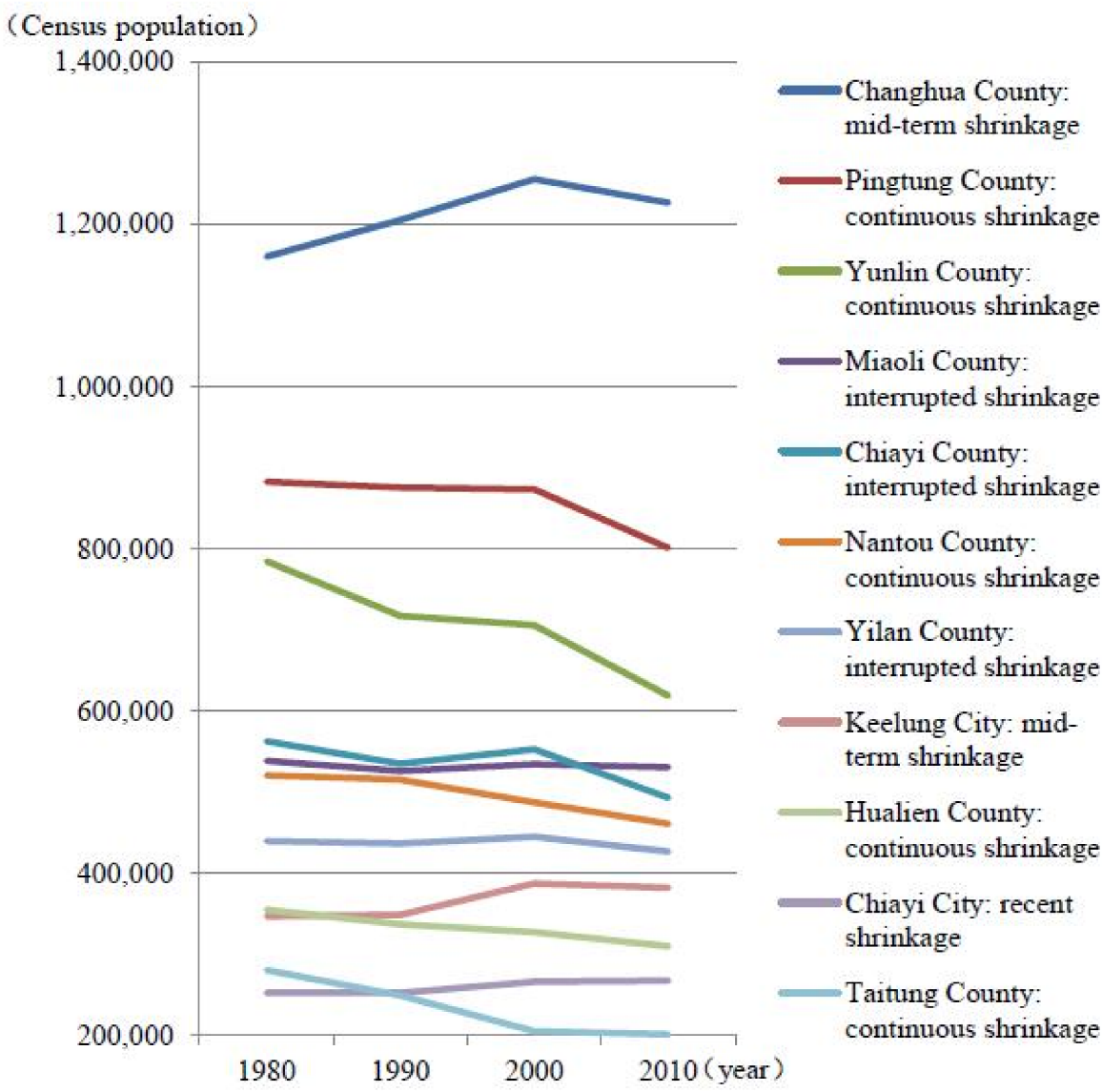

Figure 5. Time trajectory of shrinking counties based on the census population.

In terms of the trajectory of Taiwan's urban development, urbanization and a small degree of suburbanization occurred from 1970 to 1990, and suburbanization occurred from 1990 to 2000 [24]. Taiwan entered the re-urbanization stage after 2000 [70]. Five counties exhibited continuous shrinkage, indicating that the urban shrinking in Taiwan began in the 
suburbanization stage, similarly to the early shrinking of European and North American cities [71,72].

\subsubsection{Spatial Patterns of Shrinkage}

The 11 shrinking counties exhibited five spatial patterns of shrinkage, with no county exhibiting global shrinkage (Figure 6a). Hualien, Nantou, and Chiayi had semiglobal shrinkage. Keelung had central shrinkage. Pingtung had perforated shrinkage. Yilan and Taitung had two-sided shrinkage. Miaoli, Changhua, Yunlin, and Chiayi had circular shrinkage.
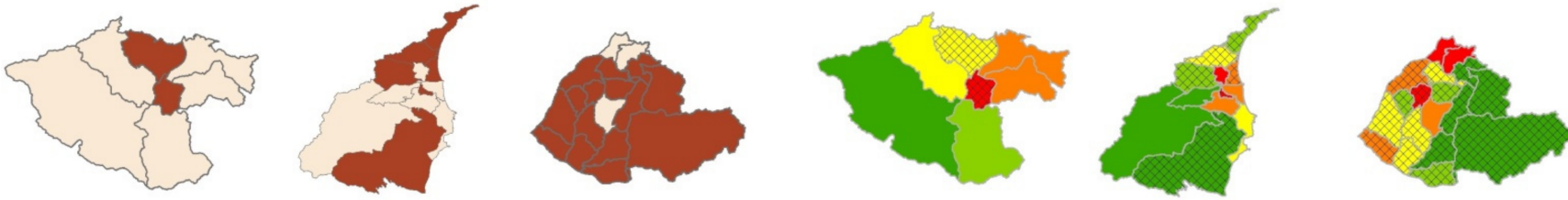

Keelung City
Central shrinking

Yilan County Miaoli County
Circular shrinkage

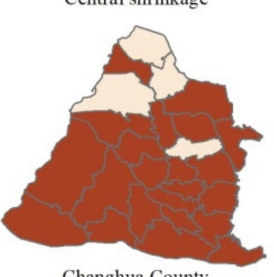

Yilan County
Two-sided shrinkage
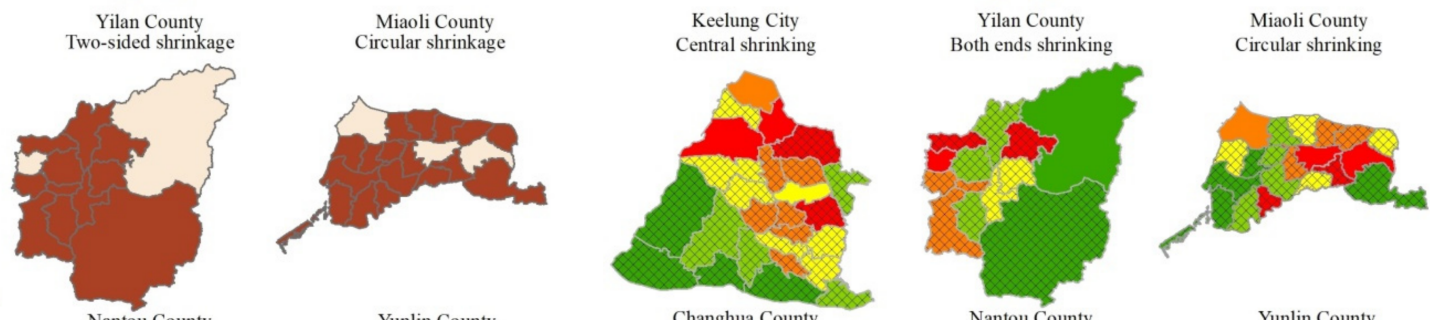

Changhua County
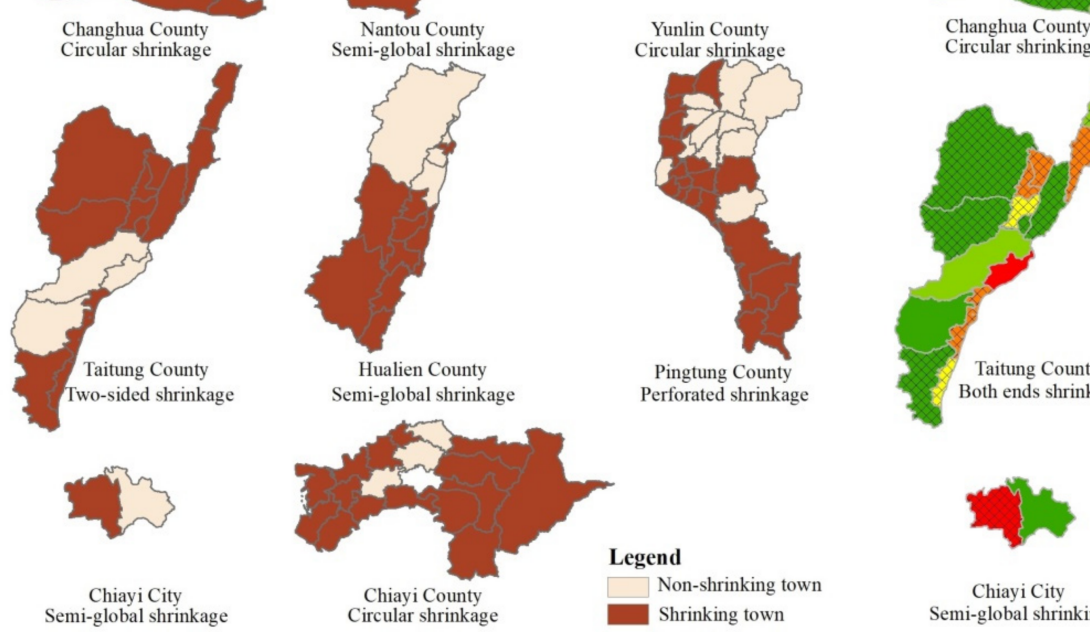

Circular shrinking
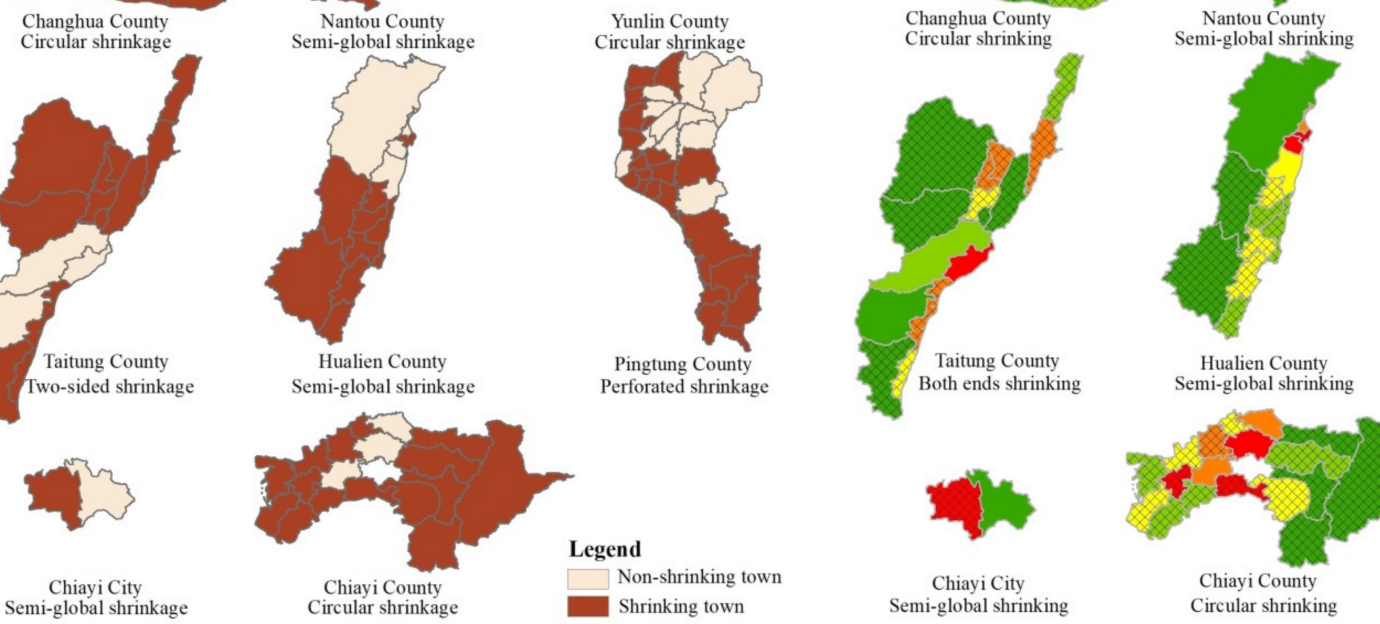

(a)
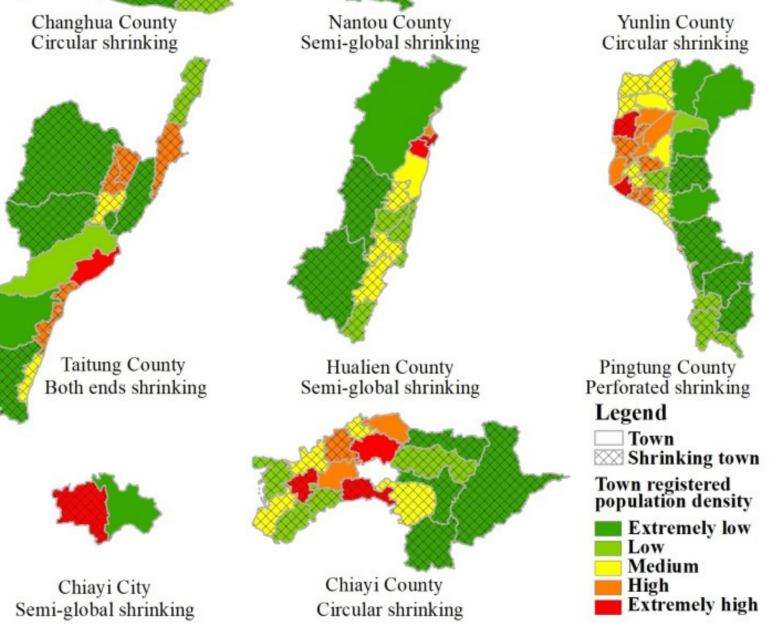

(b)

Figure 6. Spatial patterns of shrinkage: (a) spatial patterns of shrinking; (b) shrinkage and registered population density.

A map overlay analysis revealed that towns of all population densities were subject to shrinkage (Figure 6b). Among the 11 shrinking counties, 10 shrinking counties had towns with extremely high population densities; nine shrinking counties had extremely low population densities. The spatial patterns of shrinkage for the majority of the shrinking counties indicated that towns with high population densities could not avoid shrinking. The population attractiveness of high-density towns is limited.

\subsection{Spatial Autocorrelation Analysis}

\subsubsection{Global Spatial Autocorrelation Analysis}

The Global Moran's I values for each time period were greater than 0 (Figure 7), indicating a positive spatial autocorrelation among the change in towns' registered household population. This result indicates that towns with increases in their registered populations were close together and that towns with decreases in their registered populations were also close together. 

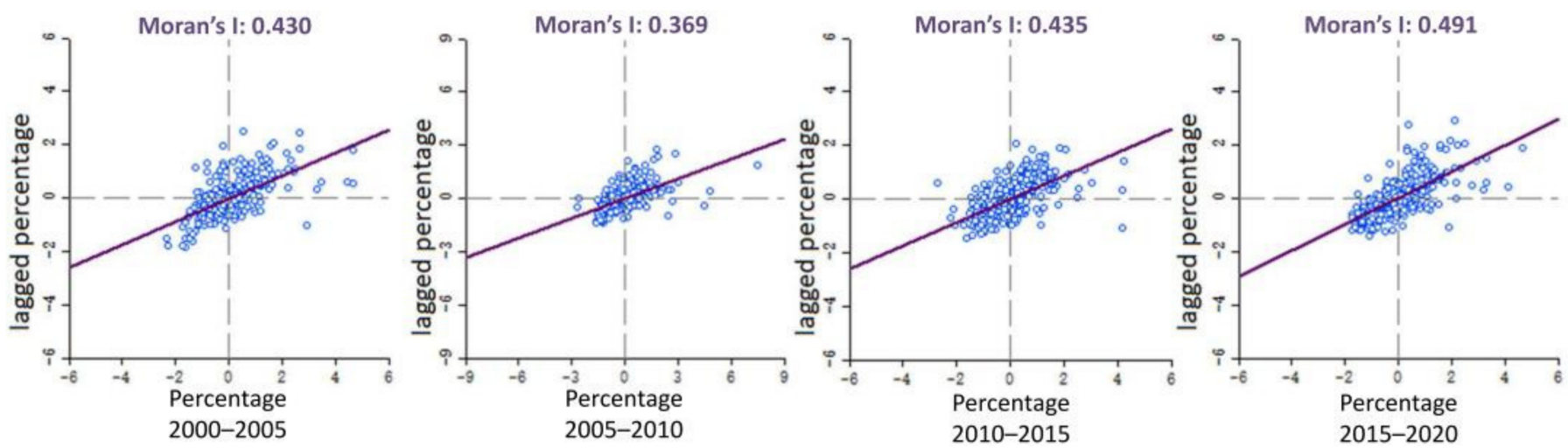

Figure 7. Global Moran's I of towns.

The Global Moran's I increased from 2005 to 2010, from 2010 to 2015, and from 2015 to 2020 , indicating that the positive spatial autocorrelation of the change in towns' registered population also increased after 2005. This result indicates that the spatial concentration of towns with large increases in registered population became increasingly pronounced. The spatial agglomeration of towns with large decreases in their registered population also became more pronounced. The total growth of the registered populations decreased after 2005 (Table 8), and shrinkage and non-shrinkage at the town level became more apparent.

Table 8. Change in total registered population of all towns during each time period.

\begin{tabular}{ccccc}
\hline Period & 2000-2005 & 2005-2010 & 2010-2015 & 2015-2020 \\
\hline $\begin{array}{c}\text { Change rate of total registered } \\
\text { population of all towns }\end{array}$ & $2.09 \%$ & $1.57 \%$ & $1.26 \%$ & $0.28 \%$ \\
\hline
\end{tabular}

\subsubsection{Local Spatial Autocorrelation Analysis}

The LISA cluster map revealed a significant local spatial correlation (Figure 8). In the LISA cluster map, "high-high" represents clusters of towns with significant increases in their registered populations. "Low-low" represents clusters of towns with significant decreases in their registered populations. "High-low" represents towns with decreases in their registered population but with increases in the registered populations of the surrounding towns. "Low-high" represents towns with increases in their registered populations but with decreases in the registered populations or surrounding towns. "No significant" indicates that the changes in the towns' registered populations were not spatially significant and that the high and low values were randomly distributed.

The spatial clustering of the changes in registered population was mainly high-high or low-low. The high-low and low-high spatial clusters were not as prominent. The high-high clusters did not noticeably change over time, whereas the low-low clusters changed substantially.

The high-high clusters were mainly concentrated in the special municipalities and in Hsinchu City and Hsinchu County. In addition, a large number of low-low clusters were observed in the provincial cities. According to the provisions of the Local Government Act, a special municipality refers to an area with more than 1.25 million people and unique needs in terms of political, economic, cultural, and metropolitan development. In 2010, Taiwan underwent county and city restructuring, the first large-scale adjustment of administrative divisions since 1950. The purpose of adjusting the administrative divisions was to promote balanced development among regions and to bridge the gap between urban and rural areas. However, the current phenomenon of shrinking cities suggests that the adjustments to the administrative divisions did not serve their intended purposes. The special municipalities increased their debt ceilings, allowing them to invest in a wide range of public resources. In addition, the Act Governing the Allocation of Government Revenues and Expenditures 
enabled the special municipalities to receive a larger amount of pooled allocations, causing urban development to become unbalanced.

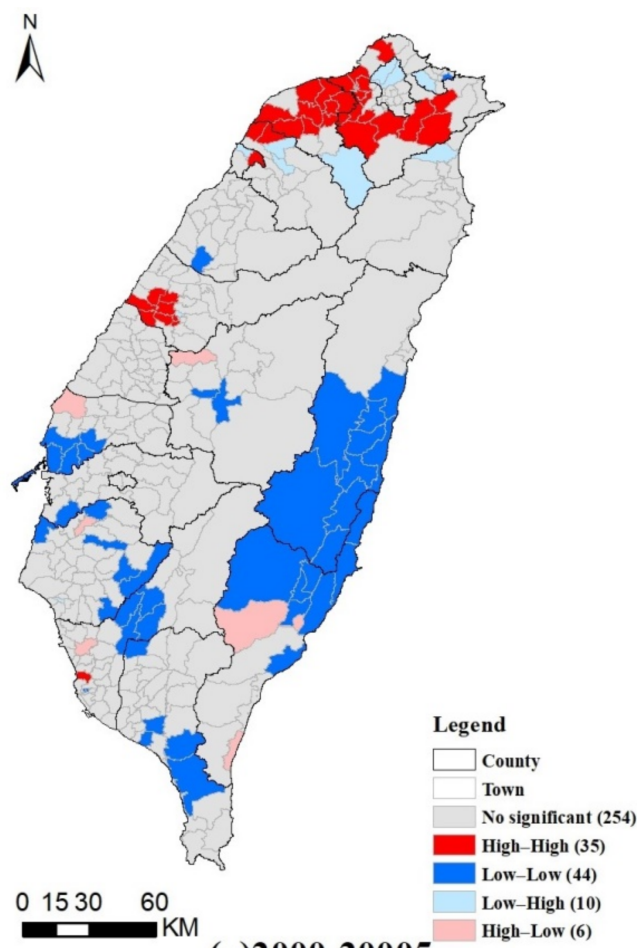

(a)2000-20005

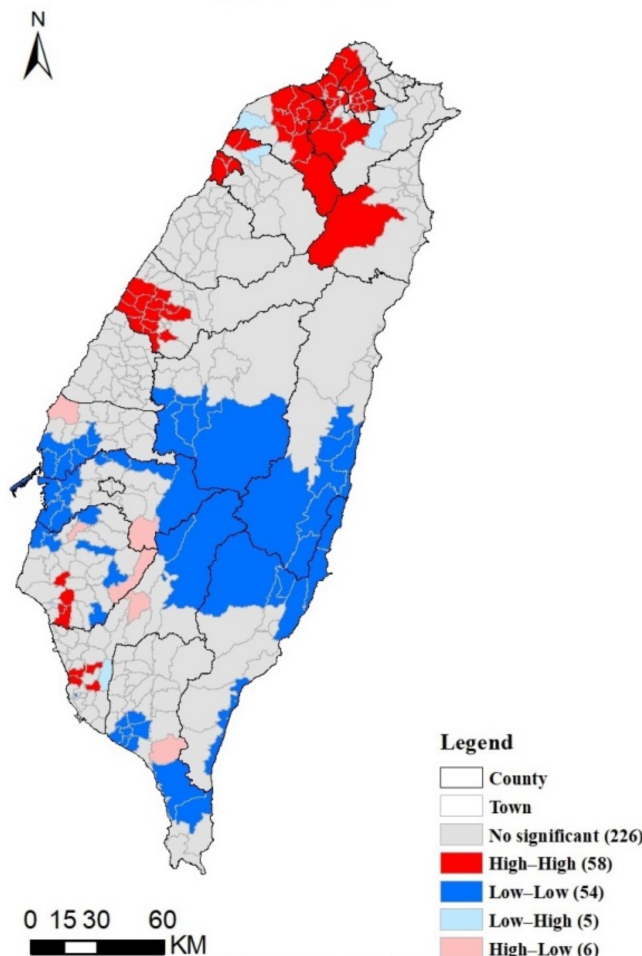

(c)2010-2015

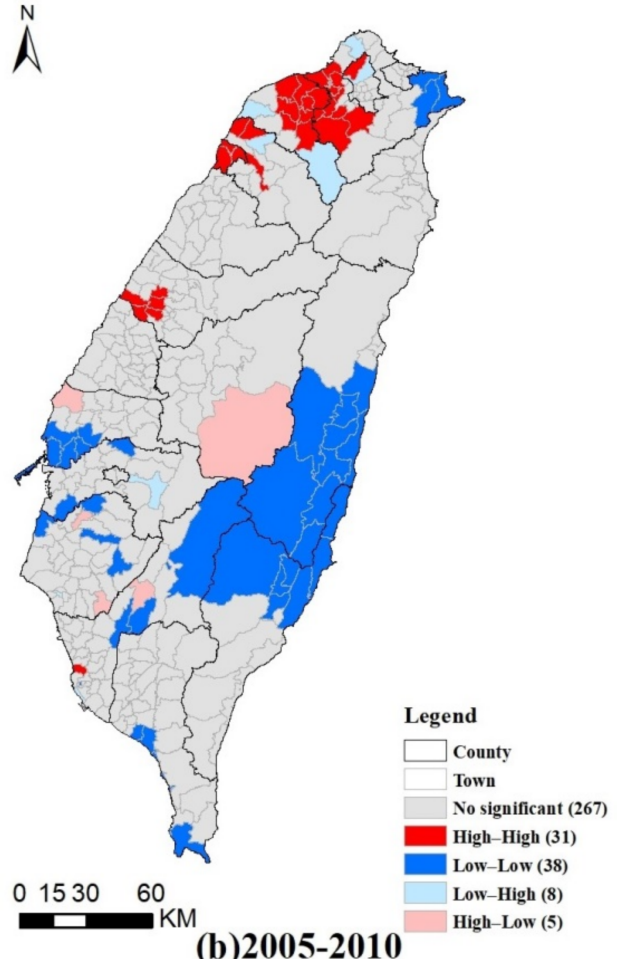

$N$

(b)2005-2010

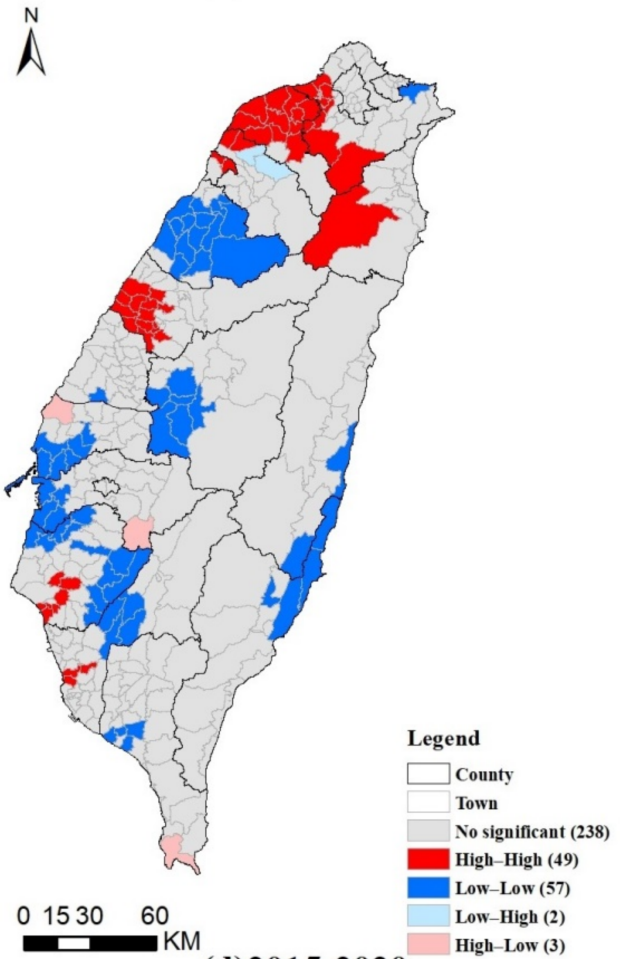

(d)2015-2020

Figure 8. LISA cluster map of the change in each town's registered population.

The "low-high" clusters appeared mainly around the Taipei Metropolitan Area, Taoyuan City, Hsinchu County, and Hsinchu City. Taipei City is the political and economic center of Taiwan. Taiwan's gateway airport is located in Taoyuan City. Hsinchu Science Park, considered the most valuable industrial area in Taiwan, is located between 
Hsinchu City and Hsinchu County. Economic factors and disadvantages in development have caused the population in this region to decline. However, the attractiveness of the entire northern region has increased with time; the number of low-high clusters has gradually decreased, with some becoming "high-high" clusters.

The gateway city of Taiwan, Taipei City, contains low-high clusters. Taipei City has the highest housing prices in Taiwan. According to the market.591 website, in 2020, the average price of a house in Taipei was as high as US $\$ 7450 / \mathrm{m}^{2}$. This price is approximately 1.9, 3.3, and 4 times the prices of houses in New Taipei City, Taoyuan City, and Keelung City, respectively. The high cost of living in Taipei City, along with the extensive development of the rail transit system and the expansion of the metropolitan area into surrounding counties and cities, led to population loss and the appearance of the low-high clusters from 2000 to 2015.

Areas of high-low clusters were observed in the central, southern, and eastern regions of Taiwan. The areas of high-low clusters experienced growth in the number of registered households. However, the growth was small, indicating that the central, southern, and eastern regions were not as attractive to residents as was the north.

\subsection{Analysis of Correlation between Urbanization and Shrinkage}

\subsubsection{Cluster Analysis Results}

Two-step cluster analysis was conducted in SPSS statistical software (version 22). The variables exhibited apparent differences (Table 9). Because all variables were continuous, Euclidean distance is used in the first step. The BIC is a valuable and objective selection criterion (Chiu et al., 2001; Norusis, 2011), and almost all previous empirical studies using two-step cluster analysis have used the BIC (Rundle-Thiele et al., 2015; Qin et al., 2019; Benassi et al., 2020). Therefore, BIC was used in the second step to evaluate each clustering result (Appendix A, Figure A1). Ultimately, 349 towns were divided into four clusters (Figure 9). Cluster 1 had 31 towns; cluster 2 had 96 towns; cluster 3 had 130 towns; and cluster 4 had 92 towns.

Table 9. Descriptive statistics for each variable.

\begin{tabular}{cccccc}
\hline $\begin{array}{c}\text { Variable } \\
\text { Abbreviation }\end{array}$ & $\mathbf{N}$ & Minimum & Maximum & Mean & $\begin{array}{c}\text { Std. } \\
\text { Deviation }\end{array}$ \\
\hline PD & 349 & 2.50 & $41,909.30$ & 2784.54 & 5593.48 \\
PPCD & 349 & 6.64 & 69.90 & 24.83 & 12.60 \\
PISI & 349 & 0.32 & $19,662.90$ & 841.73 & 2375.58 \\
PNPP & 349 & 32.29 & 99.98 & 85.17 & 15.60 \\
PNAP & 349 & 65.56 & 95.56 & 85.40 & 5.82 \\
\hline
\end{tabular}

Each cluster was named based on the centroid of clusters (Appendix A, Figure A2) and the comparison of clusters (Appendix A, Figure A3). Excluding the PNAP, the mean of the remaining four variables in clusters 1-4 gradually decreased. Therefore, the 31 towns in cluster 1 in this study were termed a core developed area. Similarly, the 96 towns in cluster 2 were termed a highly developed area; the 130 towns in cluster 3 were termed a moderately developed area; and the 92 towns in cluster 4 were termed the least developed area (Figure 9). The mean of the PNAP indicated that the age in the least developed area is the most advanced, followed by the moderately developed area. The highly developed area has the youngest population. 


\section{Clusters}

Input (Predictor) Importance

$\square 1.0 \square 0.8 \square 0.6 \square 0.4 \square 0.2 \square 0.0$

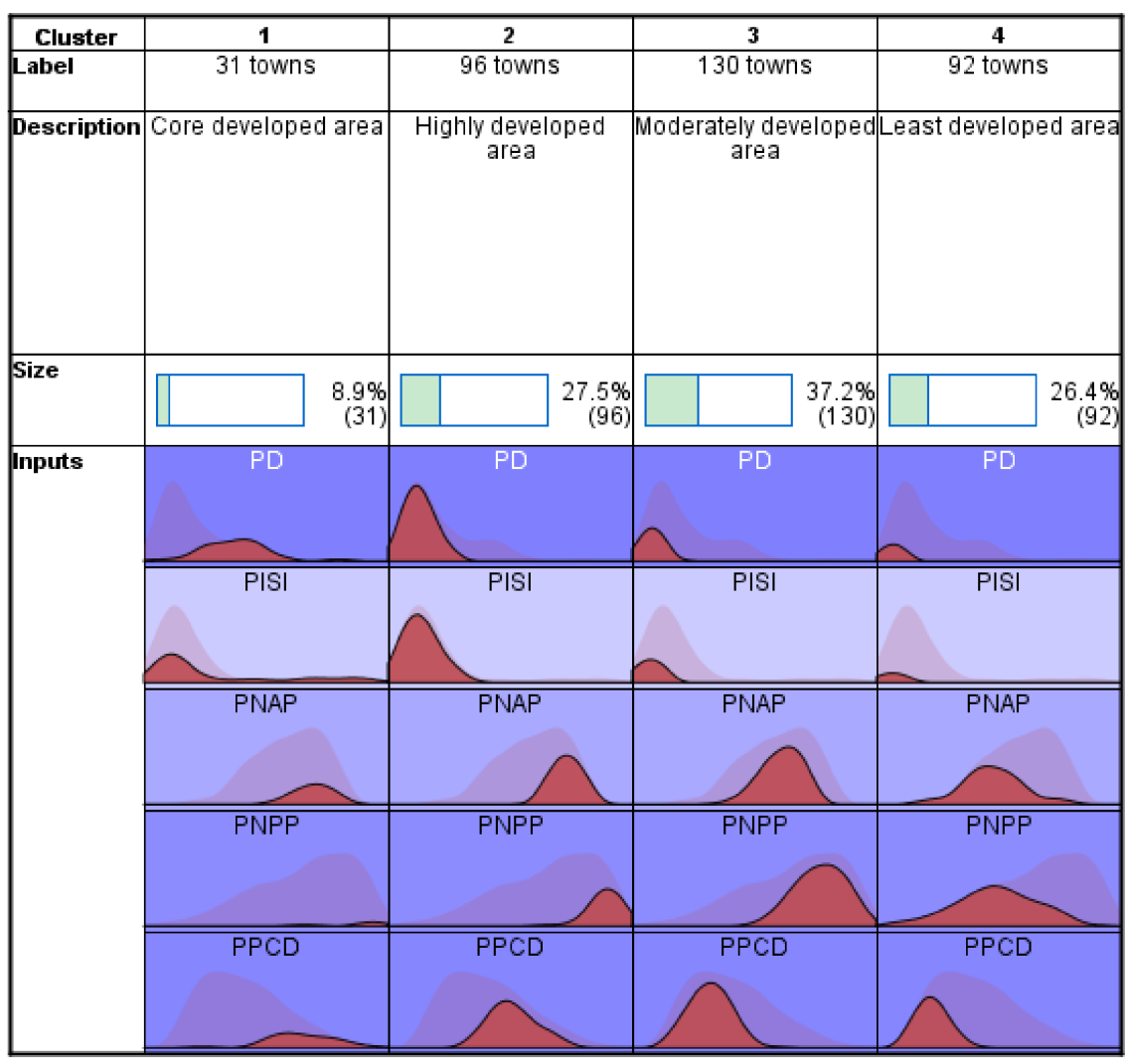

Figure 9. Two-step cluster analysis results.

Taiwan's regional development is uneven overall (Figure 10a). The northern region was the most developed, with many towns in core developed or highly developed areas. The majority of the core developed areas were in the six special municipalities. Only one part of the core developed area was adjacent to the least developed area, located in Yunlin County. The highly developed area surrounded most of the core developed area. Many towns in the southwestern region were located in the least developed area. Moderately and least developed areas were distributed throughout Taiwan. Many towns in the southwestern region were located in the least developed area. Similarly, many towns in the central region were located in the least developed area depending on the land area.

The urbanization category of the four clusters (Figure 10b) was determined based on the cluster analysis results combined with both the population scale of each town (Table 1) and the registered population density in 2020 (Figure 1b). The core developed area was categorized as the urban core. The highly developed area was categorized as the urban area. The moderately developed area was categorized as the urban periphery. The least developed area was categorized as the urban periphery or rural area. 
$\hat{\Lambda}$

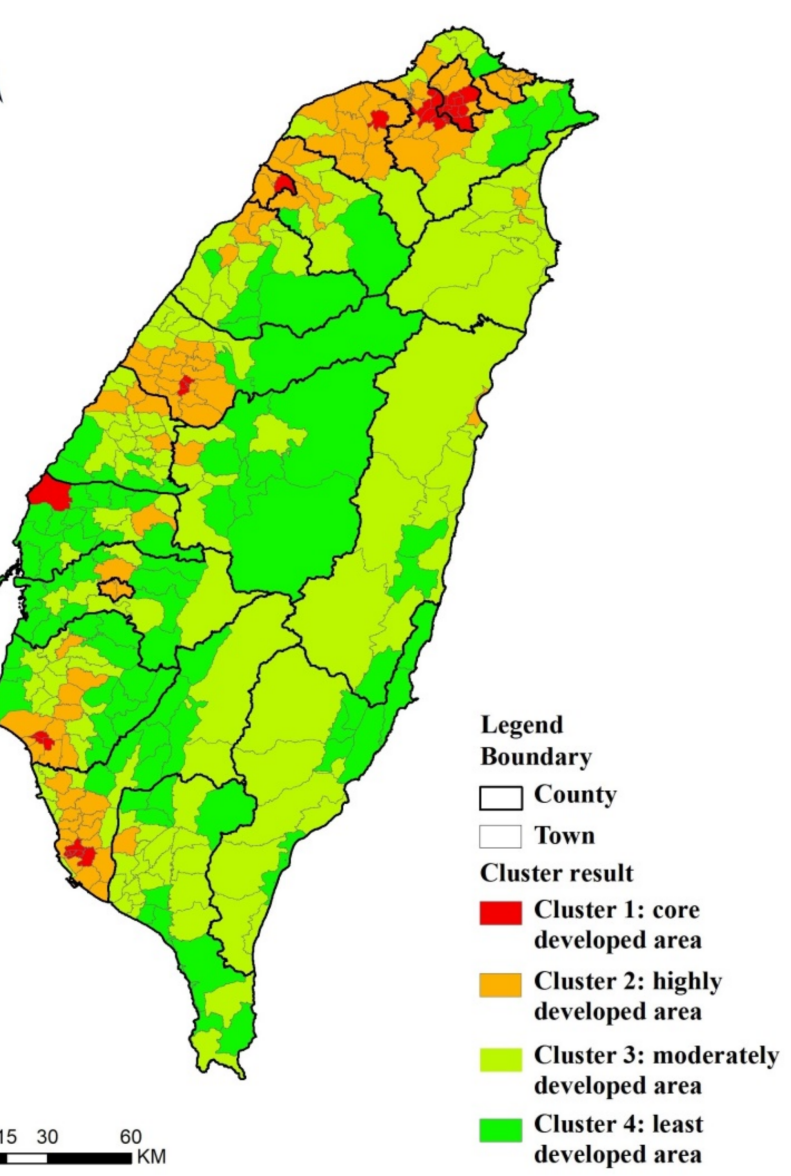

(a)

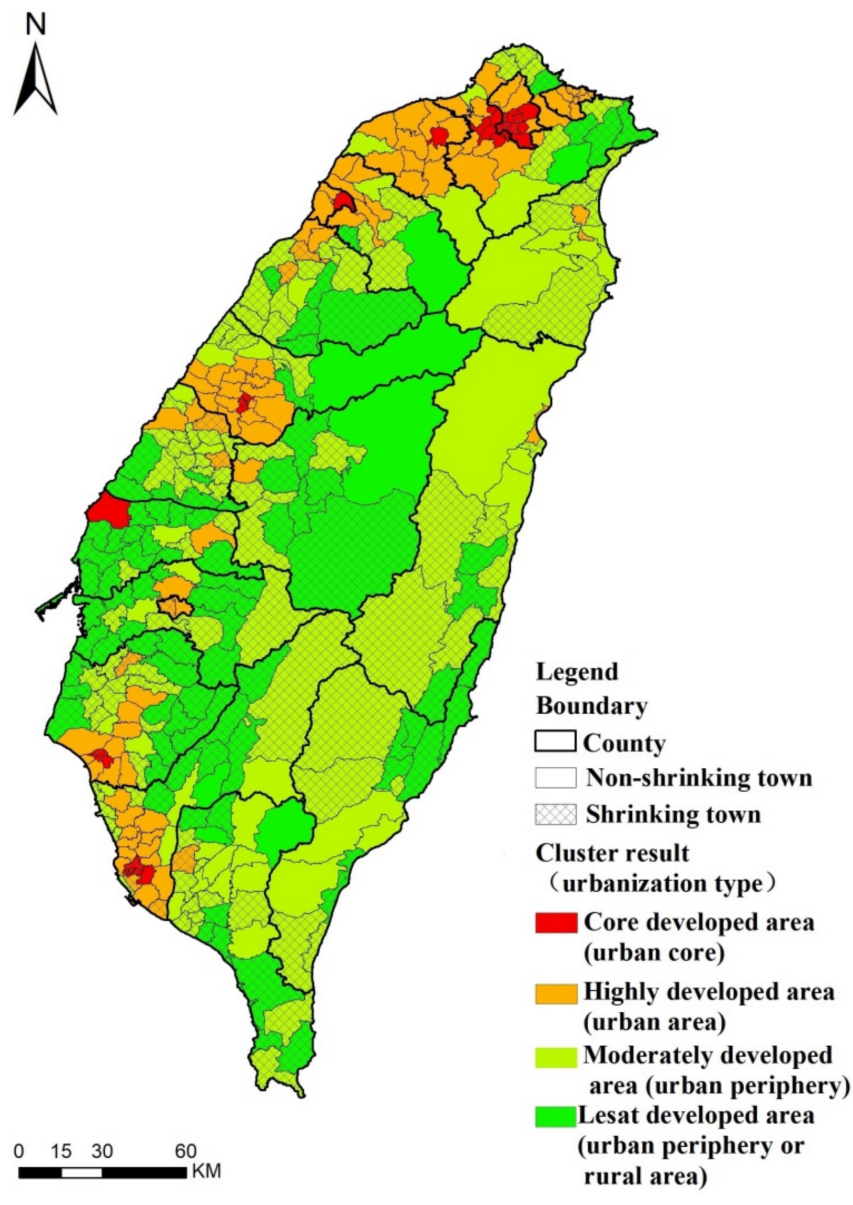

(b)

Figure 10. Cluster analysis: (a) cluster results; (b) cluster results and shrinkage.

\subsubsection{Shrinkage of Each Area}

Shrinking towns exist in the four areas, but the proportion in each area is quite different (Table 10). The highest proportion of shrinking towns is in the least developed area, followed by the moderately developed area. The lowest proportion of shrinking towns is in the highly developed area, followed by the core developed area. From the perspective of geographic relations, many shrinking towns located in moderately developed areas and least developed areas are adjacent to each other (Figure 10b).

Table 10. Proportion of shrinking towns in each area.

\begin{tabular}{ccccc}
\hline Area & Shrinking Towns & All Towns & $\begin{array}{c}\text { Proportion of } \\
\text { Shrinking Towns }\end{array}$ & Type \\
\hline Core developed area & 14 & 31 & $45.16 \%$ & Urban core \\
Highly developed area & 12 & 96 & $12.50 \%$ & Urban area \\
Moderately developed area & 87 & 130 & $66.92 \%$ & Urban periphery \\
Least developed area & 85 & 92 & $92.39 \%$ & Urban periphery or \\
rural area
\end{tabular}




\section{Discussion}

\subsection{Shrinkage and Urbanization}

The LISA cluster analysis map of the registered population changes in towns (Figure 8) and the shrinkage in the four areas (Figure 10b) jointly indicate that the difference in shrinkage was explained by urbanization.

For the least developed area, $92.39 \%$ of the towns were considered shrinking towns, and this designation indicates that the shrinkage of the urban and rural areas is severe. The least developed areas are scattered throughout the main island of Taiwan and are not concentrated in a specific region. In the LISA cluster map, the registered population of most towns in the least developed areas had no considerable changes throughout four periods. Among the four areas, the least developed area had the oldest population and the advanced age area had a generally low fertility rate. Additionally, the urbanization of other areas has attracted some people who originally belonged to the least developed area. The combined effect of these factors has led to a general shrinkage in the least developed area.

With regard to the moderately developed area, $66.92 \%$ of the towns were considered shrinking towns, and this designation indicates that the urban periphery has been shrinking substantially. The least developed areas have a higher shrinkage proportion; the population in the moderately developed areas flow to the core developed areas and the highly developed areas, as corroborated by the local spatial autocorrelation analysis. In the LISA cluster map, the changes of the registered population in most of the moderately developed areas belonged to high-low clusters in the four periods. Regarding the severity of population decline, governing the shrinkage of moderately developed areas is the most complex and urgent task at hand. The relatively low urbanization is the main reason for the shrinkage of the moderately developed areas.

In the LISA cluster map, most of the registered population changes in the core developed areas were not considerable. Nevertheless, $45.16 \%$ of the towns in the core developed are shrinking towns, and the urban core also exhibits shrinkage. In the core developed areas, high-high clusters generally appear, and this fact indicates that the population attractiveness of the urban core is weakening. The shrinkage of the core developed area is caused by suburbanization.

The lowest proportion of shrinking towns is in the highly developed areas, and the proportion of $12.50 \%$ is substantially lower than other areas. In the LISA cluster map, highhigh clusters are widespread and appear in the highly developed areas in four periods. At the same time, the population of the highly developed areas is the youngest. Therefore, in terms of geographical and spatial relations, the urban areas between the urban core and the urban periphery have substantial population attraction.

\subsection{Spatial Pattern of Shrinkage in Relation to Urbanization}

The cluster analysis results indicate that among the 11 shrinking counties, only towns in Yunlin County belong to the four categories; towns in Keelung City and Chiayi City belong to the highly developed area; towns in Taitung County belong to the moderately developed area or least developed area. In the other seven shrinking counties, towns in each shrinking county belong to the highly developed areas, moderately developed areas, or least developed areas (Figure 10a).

Keelung City and Chiayi City have areas that belong to only one category; thus, the formation of shrinking spatial patterns is unrelated to urbanization. In the other nine shrinking counties, the urbanization of non-shrinking towns is considerably higher than that of shrinking towns. Therefore, the spatial pattern of these nine shrinking counties is related to overall urbanization. Overall, the spatial pattern of most shrinking counties is related to urbanization. 


\subsection{Shrinkage Characteristics and Governance}

Among the 11 Shrinking counties, only the shrinkage spatial patterns in Keelung City and Chiayi City are not related to their urbanization types. The two shrinking counties have the most potential to reverse shrinkage because they break the relationship between the spatial pattern and shrinkage. Measured by the overall development of 349 towns on Taiwan's main island, all towns in these two counties belong to highly developed areas (urban areas). Taiwan's shrinking situation shows that the proportion of shrinking towns in highly developed regions (urban areas) is much lower than in other regions.

The two shrinking counties also have some characteristics that are conducive to shrinking governance. Regarding time characteristics (Figure 5), Keelung City is a midterm shrinkage county, and Chiayi City is a recent shrinkage county. Neither belongs to continuous shrinkage. The longer the shrinkage lasts, the harder it will be to reverse. In terms of spatial characteristics (Figure 6a), Chiayi City is a semi-global shrinkage with one shrinking town and one non-shrinking town. Keelung City belongs to the central shrinkage, the two shrinking towns are adjacent, and the area composed of these two towns is directly adjacent to five non-shrinking towns. In addition, the shrinking towns in Keelung City and Chiayi City belong to the towns with the highest population density in the county (Figure 6b). Generally, areas with high population density can attract more people. The LISA cluster map (Figure 8) shows that the registered population of Keelung City and Chiayi City has not changed significantly after 2005. In summary, if appropriate resources are invested, Keelung City and Chiayi City may attract the population of other towns to reverse the contraction.

\section{Conclusions}

From 1980 to 2020, Taiwan's total population increased from 17.97 million to 23.57 million, and the shrinkage of counties and towns was hidden by 40 years of population growth. Among Taiwan's 19 counties and 349 towns, 11 counties and 202 towns were identified as shrinking in this study. The populations of the 11 shrinking counties exhibited various time trajectories and spatial patterns. Six counties had continuous shrinkage, with their census populations decreasing from 1980. An analysis of the spatial pattern of shrinkage revealed that towns with high population densities were unable to avoid shrinkage.

An ESDA revealed a positive spatial autocorrelation in the changes in a town's registered population between 2000 and 2020. The Global Moran's I increased after 2005; this increase indicates that shrinkage and non-shrinkage in towns has become more widespread after 2005. The LISA cluster map revealed that the six special municipalities, Hsinchu County, and Hsinchu City have continued to draw in residents. The areas of population decline were not limited to the southern and eastern regions of Taiwan; many areas in northern and central Taiwan exhibited population decline. In the cluster analysis, all towns were divided into four clusters. Shrinking towns exist in all area categories, but the proportions of each area substantially differ. Urbanization and suburbanization have led to the shrinking of Taiwan, but they play opposite roles in different areas. Suburbanization is the reason that the shrinkage of the core developed areas belongs to the urban core. Urbanization is the reason that the shrinkage of the moderately developed area belongs to the urban periphery. The highly developed area is geographically located between the urban core and the urban periphery, areas which have a much lower proportion of shrinking towns than other areas. The shrinking spatial pattern of most shrinking counties is related to urbanization.

In response to the decline of the Taiwanese population as a whole, the overconcentration of metropolitan populations, and the imbalance in urban-rural development, regional revitalization has become a prominent government policy. This policy was introduced in 2019. However, the annual investment in regional revitalization is only US $\$ 470$ million, and the effects of the regional revitalization policy still require assessment. Various systems and cultural backgrounds have shaped spatial planning systems with similar characteristics, and these systems have been adapted to specific cultures, norms, and spatial 
conditions [30]. Therefore, urban shrinkage is difficult to reverse. However, this study found that among the 11 shrinking counties, Keelung City and Chiayi City have the most potential to reverse the shrinkage. The impact of urban shrinkage is omnidirectional, and the change in population is not the only criterion that can be used to identify shrinkage. Follow-up research should identify urban shrinkage in Taiwan from the perspective of vacant housing and land use. Shrinking counties have distinct spatial patterns of shrinkage, and future research must regard each shrinking county as its own case study to analyze the specific reasons for its shrinking spatial pattern. The effects of shrinking governance in the regional revitalization policy and the development of a strategy for shrinking governance in Taiwan also represent worthwhile directions for future research.

Funding: This research received no external funding.

Data Availability Statement: Not appliable.

Conflicts of Interest: The authors declare no conflict of interest.

\section{Appendix A}

\begin{tabular}{|c|c|c|c|c|}
\hline Number of Clusters & $\begin{array}{l}\text { Schwarz's } \\
\text { Bayesian } \\
\text { Criterion } \\
\text { (BIC) }\end{array}$ & BIC Change ${ }^{a}$ & $\begin{array}{c}\text { Ratio of BIC } \\
\text { Changes }^{b}\end{array}$ & $\begin{array}{c}\text { Ratio of } \\
\text { Distance } \\
\text { Measures }^{c}\end{array}$ \\
\hline 1 & 1265.591 & & & \\
\hline 2 & 932.249 & -333.342 & 1.000 & 1.446 \\
\hline 3 & 719.846 & -212.403 & .637 & 2.133 \\
\hline 4 & 651.358 & -68.488 & .205 & 2.029 \\
\hline 5 & 647.292 & -4.066 & .012 & 1.867 \\
\hline 6 & 672.300 & 25.008 & -.075 & 1.252 \\
\hline 7 & 704.054 & 31.754 & -.095 & 1.185 \\
\hline 8 & 739.998 & 35.944 & -.108 & 1.015 \\
\hline 9 & 776.274 & 36.276 & -.109 & 1.269 \\
\hline 10 & 817.275 & 41.001 & -.123 & 1.097 \\
\hline 11 & 859.823 & 42.548 & -.128 & 1.384 \\
\hline 12 & 906.813 & 46.990 & -.141 & 1.044 \\
\hline 13 & 954.287 & 47.474 & -.142 & 1.298 \\
\hline 14 & 1004.302 & 50.015 & -.150 & 1.054 \\
\hline 15 & 1054.752 & 50.450 & -.151 & 1.137 \\
\hline
\end{tabular}

Figure A1. BIC for auto-clustering.

\begin{tabular}{|c|c|c|c|c|c|c|c|c|c|c|c|}
\hline & \multicolumn{2}{|c|}{ PD } & \multicolumn{2}{|c|}{ PPCD } & \multicolumn{2}{|c|}{ PISI } & \multicolumn{2}{|c|}{ PNPP } & \multicolumn{2}{|c|}{ PNAP } \\
\hline & & Mean & Std. Deviation & Mean & Std. Deviation & Mean & Std. Deviation & Mean & Std. Deviation & Mean & Std. Deviation \\
\hline \multirow[t]{5}{*}{ Cluster } & 1 & 18033.6935 & 7720.83311 & 46.1271 & 11.09332 & 4893.5935 & 6284.00834 & 99.0971 & 3.98792 & 88.8994 & 3.46985 \\
\hline & 2 & 3242.7615 & 2485.22933 & 35.7205 & 6.71465 & 1258.8319 & 1149.44876 & 97.7534 & 2.98253 & 90.6208 & 2.33730 \\
\hline & 3 & 640.5362 & 723.74173 & 20.2992 & 5.81801 & 142.3925 & 167.65387 & 87.3531 & 7.15829 & 85.3641 & 3.37602 \\
\hline & 4 & 197.6739 & 187.75889 & 12.6872 & 3.65411 & 29.4029 & 42.20841 & 64.2441 & 12.66840 & 78.8126 & 5.18481 \\
\hline & Combined & 2784.5424 & 5593.48337 & 24.8287 & 12.59871 & 841.7346 & 2375.58401 & 85.1653 & 15.59695 & 85.3970 & 5.81946 \\
\hline
\end{tabular}

Figure A2. Centroids of clusters. 


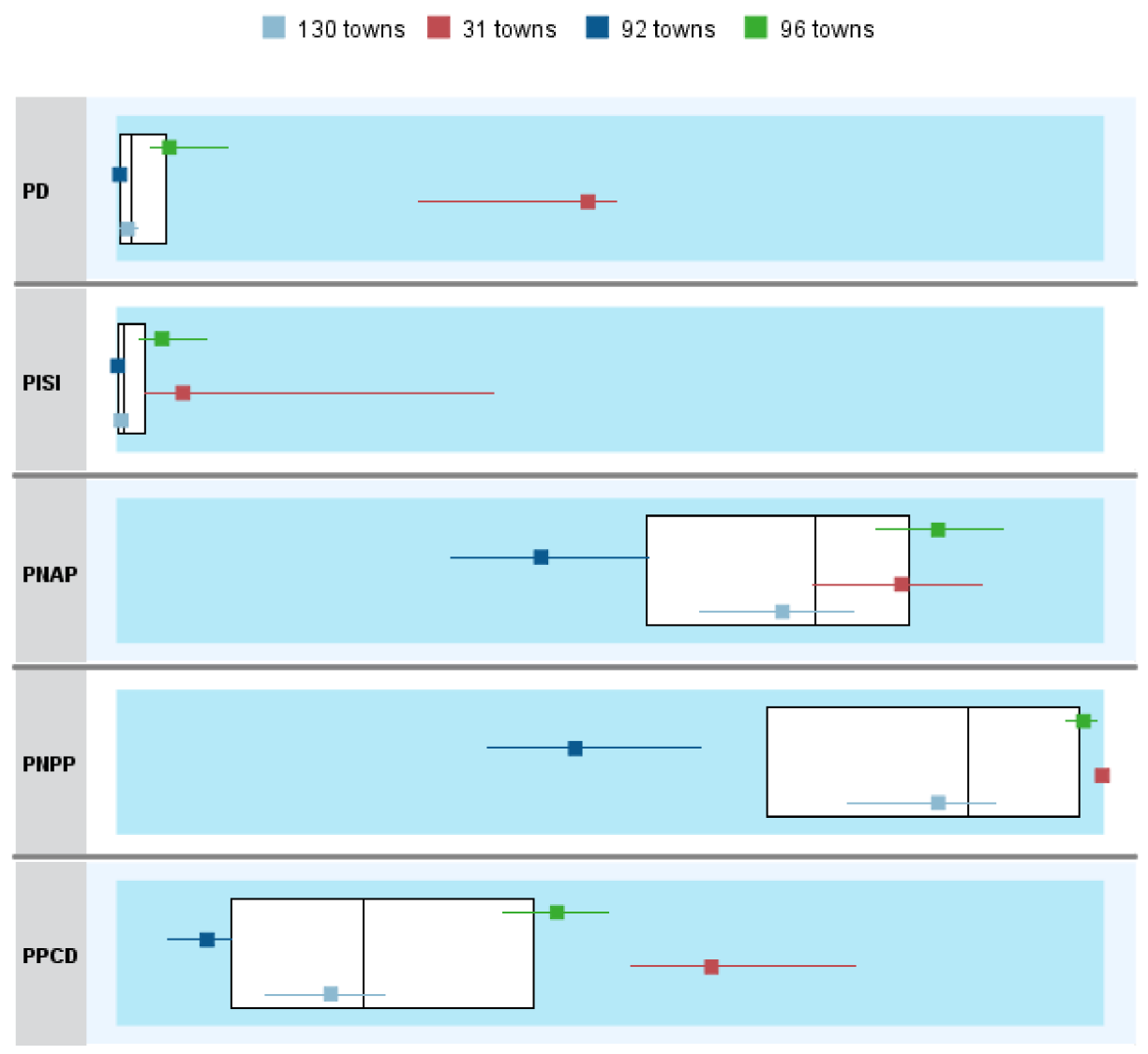

Figure A3. Comparison of clusters.

\section{References}

1. Turok, I.; Mykhnenko, V. The trajectories of European cities, 1960-2005. Cities 2007, 24, 165-182. [CrossRef]

2. Kabisch, N.; Haase, D.; Haase, A. Evolving reurbanisation? Spatio-temporal dynamics as exemplified by the East German city of Leipzig. Urban. Stud. 2010, 47, 967-990. [CrossRef]

3. UN-Habitat. State of the World's Cities 2008/9: Harmonious Cities; Routledge: London, UK, 2012.

4. Haase, A.; Rink, D.; Grossmann, K.; Bernt, M.; Mykhnenko, V.J.E. Conceptualizing urban shrinkage. Environ. Plan. A 2014, 46, 1519-1534. [CrossRef]

5. Long, Y.; Wu, K. Shrinking cities in a rapidly urbanizing China. Environ. Plan. A 2016, 48, 220-222. [CrossRef]

6. Yang, Z. Sustainability of Urban Development with Population Decline in Different Policy Scenarios: A Case Study of Northeast China. Sustainability 2019, 11, 6442. [CrossRef]

7. Zhou, Y.; Li, C.; Ma, Z.; Hu, S.; Zhang, J.; Liu, W. Identification of shrinkage and growth patterns of a shrinking city in China based on nighttime light data: A case study of Yichun. Sustainability 2019, 11, 6906. [CrossRef]

8. Uemura, T. Population Decline, Infrastructure and Sustainability. Ph.D. Thesis, London School of Economics and Political Science, London, UK, 2014.

9. Kawai, K.; Suzuki, M.; Shimizu, C. Shrinkage in Tokyo's central business district: Large-scale redevelopment in the spatially shrinking office market. Sustainability 2019, 11, 2742. [CrossRef]

10. Joo, Y.-M.; Seo, B.J.C. Dual policy to fight urban shrinkage: Daegu, South Korea. Cities 2018, 73, 128-137. [CrossRef]

11. Lee, J.-W. Transforming Unused Spaces in a Shrinking City through Individuals' Spontaneous Occupation Activities: The Case of Janghang, South Korea. Sustainability 2020, 12, 6621. [CrossRef]

12. Jeon, Y.; Kim, S. Housing abandonment in shrinking cities of East Asia: Case study in Incheon, South Korea. Urban Stud. 2020, 57, 1749-1767. [CrossRef]

13. Howe, S.R.; Bier, T.; Allor, D.; Finnerty, T.; Green, P. The shrinking central city amidst growing suburbs: Case studies of Ohio's inelastic cities. Urban Geogr. 1998, 19, 714-734. [CrossRef]

14. Wiechmann, T.; Bontje, M. Responding to Tough Times: Policy and Planning Strategies in Shrinking Cities. Eur. Plan. Stud. 2015, 23, 1-11. [CrossRef]

15. Häußermann, H.; Siebel, W. Die schrumpfende Stadt und die Stadtsoziologie. In Soziologische Stadtforschung; VS Verlag für Sozialwissenschaften: Wiesbaden, Germany, 1988; pp. 78-94.

16. Rusk, D. Cities without Suburbs; Woodrow Wilson Center Press: Washington, DC, USA, 1993. 
17. Clark, D. Urban Decline, 2nd ed.; Routledge: New York, NY, USA, 2013.

18. Lotscher, L. Shrinking East German Cities? Geogr. Pol. 2005, 78, 79-98.

19. Hollander, J.B.; Pallagst, K.; Schwarz, T.; Popper, F.J. Planning shrinking cities. Prog. Plan. 2009, 72, $223-232$.

20. Hollander, J.B.; Németh, J. The bounds of smart decline: A foundational theory for planning shrinking cities. Hous. Policy Debate 2011, 21, 349-367. [CrossRef]

21. Gao, S. A review of researches on shrinking cities. Urban Plan. Forum 2015, 3, 44-49.

22. $\mathrm{Wu}, \mathrm{K}$. Urban shrinkage in the Beijing-Tianjin-Hebei Region and Yangtze River Delta: Pattern, trajectory and factors. In Shrinking Cities in China; Springer: Singapore, 2019; pp. 43-61.

23. Gao, S. Tracing the phenomenon, concept and research of shrinking cities. Urban Plan. Int. 2017, 32, 50-58. [CrossRef]

24. Liu, P.K.; Tung, A.-C. Urban development in Taiwan: Retrospect and prospect. J. Popul. Stud. 2003, 26, 1-25.

25. Huang, S.J. On Taiwan's Level of Urbanization. Taiwan. J. Sociol. 2002, 27, 163-205.

26. Champion, T. Urbanization, suburbanization, counterurbanization and reurbanization. In Handbook of Urban Studies; Paddison, P., Ed.; Sage Publications: London, UK; Thousand Oaks, CA, USA; New Delhi, India, 2001; pp. 143-161.

27. Van den Berg, L.; Drewett, R.; Klaassen, L.H.; Rossi, A.; Vijverberg, C.H.T. A Study of Growth and Decline: Urban Europe; Pergamon Press: Oxford, UK, 1982.

28. Jackson, K.T. Crabgrass Frontier: The Suburbanization of the United States; Oxford University Press: New York, NY, USA, 1987.

29. Wiechmann, T.; Pallagst, K.M. Urban shrinkage in Germany and the USA: A comparison of transformation patterns and local strategies. Int. J. Urban Reg. Res. 2012, 36, 261-280. [CrossRef]

30. Pallagst, K.; Fleschurz, R.; Nothof, S.; Uemura, T. Shrinking cities: Implications for planning cultures? Urban Stud. 2021, 58, 164-181. [CrossRef]

31. Taiwan News. Available online: https:/ / www.taiwannews.com.tw/en/news/3584484 (accessed on 29 June 2021 ).

32. Spatial Planning Act. Available online: https://law.moj.gov.tw/ENG/LawClass/LawAll.aspx?pcode=D0070230 (accessed on 28 June 2021).

33. Lin, H.C.; Lee, H.L.; Hsu, S.M.; Lin, K.J.; Lee, D.H.; Chang, C.C.; Hsu, S.H. Baseline forecasting for Taiwan's population in the face of low fertility rate and ageing problems. Taiwan Econ. Forecast. Policy 2015, 46, 113-156.

34. Chien, T.Y. A Typology Study of Shrinking Cities in Taiwan Based on the Transformation of Urban Structures in Population and Industry. Master's Thesis, National Cheng Kung University, Tainan, Taiwan, 2014.

35. Wu, H.Y. A Study of Shrinking Trajectory in Taiwan Main Island Cities. Master's Thesis, National Cheng Kung University, Tainan, Taiwan, 2017.

36. Liu, I.H. A Study of the Population Distribution of Shrinking City in the Island of Taiwan. Master's Thesis, Feng Chia University, Taichung, Taiwan, 2018.

37. Pallagst, K. The interdependence of shrinking and growing: Processes of urban transformation in the US in the Rust Belt and Beyond. In Shrinking Cities: International Perspectives and Policy Implications; Pallagst, K., Wiechmann, T., Martinez-Fernandez, C., Eds.; Routledge: New York, NY, USA, 2014; pp. 59-77.

38. Chen, M.-M.; Chen, W.-L.; Lee, C.; Lai, S. Analysis on Household Migration Registration-Problems and Recommendations on Inconsistency in Registered Address and Factual Living Address; Ministry of the Interior: Taipei, Taiwan, 2017.

39. Chang, H.Y.; Lin, M.C.; Hung, Y.T.; Lin, S.H. Comparisons among the Household Registry, Stay, and Migrated Populations in Taiwan: Evidence from the Data of 2001 Taiwan National Health Interview Survey. Surv. Res. 2003, 14, 5-29.

40. Chen, C.N.; Liu, P.K.C. An evaluation of Taiwan census 2000: A comparison of census and registered populations. J. Popul. Stud. 2003, 25, 1-56.

41. Yen, B.S.; Yue, J.C. An international study of 2010 population census methods. J. Popul. Stud. 2010, 203-229. Available online: https: / / www.airitilibrary.com/Publication/alDetailedMesh?DocID=10183841-201006-201010180080-201010180080-203-229 (accessed on 1 September 2021).

42. Wiechmann, T.; Wolff, M. Urban shrinkage in a spatial perspective-operationalization of shrinking cities in Europe 1990-2010. In AESOP-ACSP Joint Congress; ResearchGate: Dublin, Ireland, 2013; Volume 1519. Available online: https:/ / www.researchgate.net/profile/Manuel-Wolff-2/publication/290820418_Urban_Shrinkage_in_a_Spatial_Perspective_ -_Operationalization_of_Shrinking_Cities_in_Europe_1990_-2010/links/569c084d08aeeea985a5ad18/Urban-Shrinkage-in-aSpatial-Perspective-Operationalization-of-Shrinking-Cities-in-Europe-1990-2010.pdf (accessed on 1 September 2021).

43. Alves, D.; Barreira, A.P.; Guimarães, M.H.; Panagopoulos, T. Historical trajectories of currently shrinking Portuguese cities: A typology of urban shrinkage. Cities 2016, 52, 20-29. [CrossRef]

44. Du, Z.W.; Zhang, H.O.; Ye, Y.Y.; Jin, L.X.; Wang, C.J. Spatiotemporal Evolution and Influences of Urban Population Shrinkage in Guangdong Since 2000. Trop. Geogr. 2019, 39, 20-28.

45. Zhang, X.L.; Zhang, M.D.; Xiao, H. Study on spatial pattern and formation mechanism of urban contraction in ChengduChongqing city cluster. J. Chongqing. Univ. 2018, 24, 1-14.

46. Anselin, L.; Bao, S. Exploratory spatial data analysis linking SpaceStat and ArcView. In Recent Developments in Spatial Analysis; Fischer, M.M., Getis, A., Eds.; Springer: Berlin, Germany, 1997; pp. 35-59.

47. Birch, C.P.; Chikukwa, A.C.; Hyder, K.; Vilas, V.J.D.R. Spatial distribution of the active surveillance of sheep scrapie in Great Britain: An exploratory analysis. BMC Vet. Res. 2009, 5, 1-14. [CrossRef] 
48. Zhang, W.; Wang, M.Y. Spatial-temporal characteristics and determinants of land urbanization quality in China: Evidence from 285 prefecture-level cities. Sustain. Cities Soc. 2018, 38, 70-79. [CrossRef]

49. Getis, A.; Ord, J.K. The analysis of spatial association by use of distance statistics. In Perspectives on Spatial Data Analysis; Anselin, L., Rey, S.J., Eds.; Springer: Berlin, Germany, 2010; pp. 127-145.

50. Stone, S.B. A more accurate measure of local public goods: Overlapping government combinations as units of analysis. Urban Stud. Res. 2014, 2014, 1-8. [CrossRef]

51. Anselin, L. Local indicators of spatial association-LISA. Geogr. Anal. 1995, 27, 93-115. [CrossRef]

52. Karayazi, S.S.; Dane, G.; de Vries, B. Utilizing Urban Geospatial Data to Understand Heritage Attractiveness in Amsterdam. ISPRS Int. J. Geo-Inf. 2021, 10, 198. [CrossRef]

53. Kaufman, L.; Rousseeuw, P.J. Finding Groups in Data: An Introduction to Cluster Analysis, 99th ed.; John Wiley \& Sons: Hoboken, NJ, USA, 2009.

54. Liu, C.-Y.; Hung, Y.-T.; Chuang, Y.-L.; Chen, Y.-J.; Weng, W.-S.; Liu, J.-S.; Liang, K. Incorporating development stratification of Taiwan townships into sampling design of large scale health interview survey. J. Health Manag. 2006, 4, 1-22.

55. MacQueen, J. Some methods for classification and analysis of multivariate observations. In Proceedings of the Fifth Berkeley Symposium on Mathematical Statistics and Probability; University of California Press: Berkeley, CA, USA, 1967; Volume 1, pp. $281-297$.

56. Bacher, J.; Wenzig, K.; Vogler, M. SPSS TwoStep Cluster-a first evaluation. In RC33 Sixth International Conference on Social Science Methodology; Barbara Budrich Publishers: Amsterdam, The Netherlands; Opladen, Germany, 2004.

57. Frades, I.; Matthiesen, R. Overview on Techniques in Cluster Analysis. In Bioinformatics Methods in Clinical Research; Humana Press: Totowa, New Jersey, 2010; pp. 81-107.

58. Brian, S.E.; Sabine, L.; Morven, L.; Stahl, D. Cluster Analysis, 5th ed.; John Wiley and Sons, Ltd., Publication: Hoboken, NJ, USA, 2011.

59. Benassi, M.; Garofalo, S.; Ambrosini, F.; Sant'Angelo, R.P.; Raggini, R.; De Paoli, G.; Ravani, C.; Giovagnoli, S.; Orsoni, M.; Piraccini, G. Using Two-Step Cluster Analysis and Latent Class Cluster Analysis to Classify the Cognitive Heterogeneity of Cross-Diagnostic Psychiatric Inpatients. Front. Psychol. 2020, 11, 1085. [CrossRef]

60. Bezdek, J.C.; Ehrlich, R.; Full, W. FCM: The fuzzy c-means clustering algorithm. Comput. Geosci. 1984, 10, 191-203. [CrossRef]

61. Mai, D.S.; Ngo, L.T. Semi-supervised fuzzy C-means clustering for change detection from multispectral satellite image. In 2015 IEEE International Conference on Fuzzy Systems; IEEE: Istanbul, Turkey, 2015; pp. 1-8.

62. Pavlis, M.; Dolega, L.; Singleton, A. A modified DBSCAN clustering method to estimate retail center extent. Geogr. Anal. 2018, 50, 141-161. [CrossRef]

63. Lee, I.; Cai, G.; Lee, K. Exploration of geo-tagged photos through data mining approaches. Expert Syst. Appl. 2014, 41, 397-405. [CrossRef]

64. Chiu, T.; Fang, D.; Chen, J.; Wang, Y.; Jeris, C. A Robust and Scalable Clustering Algorithm for Mixed Type Attributes in Large Database Environment. In Proceedings of the Seventh Acm Sigkdd International Conference on Knowledge Discovery and Data Mining, San Francisco, CA, USA; Association for Computing Machinery Publisher: New York, NY, USA, 2001; pp. $263-268$.

65. Rundle-Thiele, S.; Kubacki, K.; Tkaczynski, A.; Parkinson, J. Using two-step cluster analysis to identify homogeneous physical activity groups. Mark. Intell. Plan. 2015, 44, 522-537. [CrossRef]

66. Qin, H.; Huang, Q.; Zhang, Z.; Lu, Y.; Li, M.; Xu, L.; Chen, Z. Carbon dioxide emission driving factors analysis and policy implications of Chinese cities: Combining geographically weighted regression with two-step cluster. Sci. Total Environ. 2019, 684, 413-424. [CrossRef]

67. Okazaki, S. Lessons learned from i-mode: What makes consumers click wireless banner ads? Comput. Human Behav. 2007, 23, 1692-1719. [CrossRef]

68. Norušis, M.J. IBM SPSS Statistics 19 Statistical Procedures Companion; Prentice Hall: Upper Saddle River, NJ, USA, 2011.

69. Satish, S.; Bharadhwaj, S. Information search behaviour among new car buyers: A two-step cluster analysis. IIMB Manag. Rev. 2010, 22, 5-15. [CrossRef]

70. Dai, X.C. The compact development and policy guidance in the process of urbanization in Taiwan. Urban Plan. Int. 2013, 28, 71-77.

71. Weaver, R.C. The Suburbanization of America or the Shrinking of the Cities. Civ. Rights Dig. 1977, 9, 2-11.

72. Wiechmann, T. Errors expected-Aligning urban strategy with demographic uncertainty in shrinking cities. Int. Plan. Stud. 2008, 13, 431-446. [CrossRef] 